\title{
联吡啶金属配合物在偶联反应中的应用
}

\author{
李英俊李志朋李兴*常宏宏魏文珑*
}

(太原理工大学化学化工学院生物与制药工程系 太原 030024)

\begin{abstract}
摘要 联吡啶类配体具有超强的氧化还原稳定性和结构易修饰的性质, 被广泛地用于合成金属螯合配合物或直接当作 配体使用, 在有机合成中的应用也变的越来越重要. 主要从 $\mathrm{C}-\mathrm{C}, \mathrm{C}-\mathrm{N}, \mathrm{C}-\mathrm{S}, \mathrm{C}-\mathrm{O}$ 和 $\mathrm{C}-\mathrm{Se}$ 键的形成角度概括了联 吡啶配体在各种偶联反应中应用的研究进展.
\end{abstract}

关键词 联吡啶金属配合物; 偶联; $\mathrm{C}-\mathrm{C}$ 键; C- $\mathrm{N}$ 键; $\mathrm{C}-\mathrm{S}$ 键; $\mathrm{C}-\mathrm{O}$ 键 $; \mathrm{C}-\mathrm{Se}$ 键

\section{Application of Bipyridyl Complexes in Coupling Reactions}
Li, Yingjun
Li, Zhipeng
Li, Xing*
Chang, Honghong
Wei, Wenlong*
(College of Chemistry and Chemical Engineering, Taiyuan University of Teconology, Taiyuan 030024)

\begin{abstract}
The bipyridyl ligands have been extensively used as metal chelating complexes or directly utilized as ligands due to their robust redox stability and ease of functionalization which also become more and more important in the application of the organic synthesis. This article mainly describes the application of bipyridyl complexes in coupling reactions for the formation of $\mathrm{C}-\mathrm{C}, \mathrm{C}-\mathrm{N}, \mathrm{C}-\mathrm{S}, \mathrm{C}-\mathrm{O}$ and $\mathrm{C}-\mathrm{Se}$ bonds.
\end{abstract}

Keywords bipyridyl complex; coupling; $\mathrm{C}-\mathrm{C}$ bond; $\mathrm{C}-\mathrm{N}$ bond; $\mathrm{C}-\mathrm{S}$ bond; $\mathrm{C}-\mathrm{O}$ bond; $\mathrm{C}-\mathrm{Se}$ bond

在 20 世纪末期，联吡啶及其衍生物作为配体被广 泛应用于与各种金属离子络合形成更有效的配合物催 化剂来促进所研究反应的顺利进行, 并取得好了的结 果. 到如今联吡啶类金属配合物已经成为使用最广泛的 配合物催化剂之一, 它们被广泛应用于各种类型的有机 合成反应中 ${ }^{[1,2]}$. 和一些其它配体如双阴离子的邻苯二 酚和单阴离子的乙酰丙酩离子衍生物等配体相比, 联吡 啶是一种弱碱性双齿配体，经过衍生，可以制得二齿、 三齿或四齿甚至更多齿的相关配体, 这种性质被广泛地 应用在金属联吡啶类配合物的设计和合成上 ${ }^{[3]}$.

构建新的 $\mathrm{C}-\mathrm{C}$ 键 ${ }^{[4]}, \mathrm{C}-\mathrm{N}$ 键 ${ }^{[5]}$ 和 $\mathrm{C}-\mathrm{S}$ 键 ${ }^{[6]}$ 或者其 它 $\mathrm{C}-\mathrm{X}$ ( $\mathrm{X}$ 代表杂原子)键一直是有机化学研究的热点 和重点 ${ }^{[7,8]}$, 而最近二三十年对它们的研究主要集中在 催化剂的研究与开发上 ${ }^{[9 \sim 14]}$, 而其中针对配合物催化剂 来说, 主要的工作是寻找各种简单易得而且有效的配 体. 最近 10 多年, 科研工作者们发现联吡啶及其衍生物 作为配体应用到形成 $\mathrm{C}-\mathrm{C}, \mathrm{C}-\mathrm{N}, \mathrm{C}-\mathrm{S}, \mathrm{C}-\mathrm{O}$ 和 $\mathrm{C}-$ $\mathrm{Se}$ 键中也取得了非常好的效果. 据此, 本文从成键的角
度，综述了最近几年内联吡啶及其衍生物作为配体(图 1)与各种金属络合配位后形成新的配合物来催化构建 $\mathrm{C}-\mathrm{C}, \mathrm{C}-\mathrm{N}, \mathrm{C}-\mathrm{S}, \mathrm{C}-\mathrm{O}$ 和 $\mathrm{C}-\mathrm{Se}$ 键的研究进展.

\section{1 联吡啶配体在偶联反应中的应用}

\section{$1.1 \mathrm{C}-\mathrm{C}$ 键的形成}

\subsubsection{Mizoroki-Heck 偶联反应}

钯催化芳基卤化物和烯烃的反应，称为 MizorokiHeck 偶联，也称 Heck 偶联，它在有机合成中是形成 C - $\mathrm{C}$ 键最有效的方法之一. Mizoroki 等于 20 世纪 60 年 代首次报道了芳基卤代烃与烯烃的偶联反应 ${ }^{[15]}$, Heck 等 ${ }^{[16]}$ 则对该反应作了进一步的深入研究.

2003 年, Nájera 等 ${ }^{[17]}$ 报道了把联吡啶配体 L1 和 L2 分别与 $\mathrm{H}_{2} \mathrm{PdCl}_{4}$ 络合形成的 $\mathrm{Pd}$ 类催化剂 Cat*1 和 Cat*2 用于催化卤代芳烃与丙烯酸丁酯或对氯苯乙烯的 Heck 偶联中 (Eq. 1). 通过对催化剂的笁选可知虽然催化剂 Cat*1 和 Cat*2 都能使卤代芳烃进行 Heck 偶联，但在水

\footnotetext{
*E-mail: weiwenlong@tyut.edu.cn

Received September 27, 2013; revised November 19, 2013; accepted December 13, 2013.

Project supported by the Natural Science Foundation of Shanxi Province (Nos. 2012021007-2, 2011011010-2) and the Scientific and Technological Innovation Programs of Higher Education Institutions in Shanxi Province (No. 20120006).

山西省自然科学基金(Nos. 2012021007-2, 2011011010-2)及山西省高等教育机构科技创新项目基金(No. 20120006)资助项目.
} 


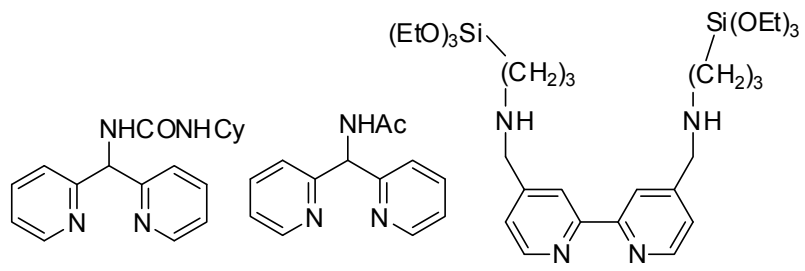

L1

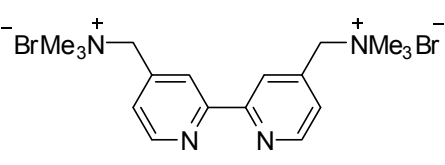

L4

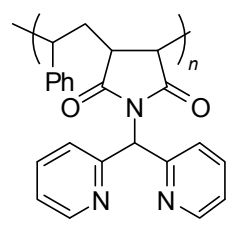

L5

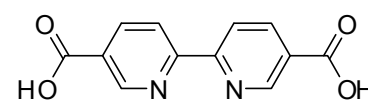

L6

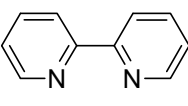

L7

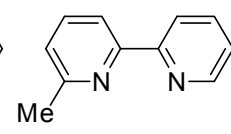

L8

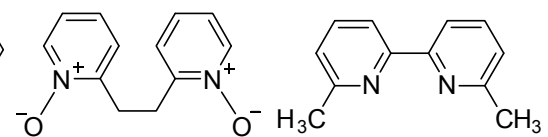

L10

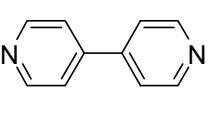

L11

图 1 应用于偶联反应中的联吡啶配体

Figure 1 Bipyridyl ligands applied in the coupling reactions

相中, Cat*1 比 Cat*2 具有更好的催化效果. 为了抑制丙 烯酸酯的水解, 该反应需要以二异丙基胺为碱. 经过优 化篎选，该反应在催化剂 Cat*1 的作用下， $N$-甲基吡咯 烷酮 (NMP) 与水作混合溶剂, 二异丙基胺作碱, 在 $140 \sim 160{ }^{\circ} \mathrm{C}$ 之间进行. 碘苯与烯烃的反应可在少量催 化剂( $0.0001 \sim 0.01 \mathrm{~mol} \%$ ) 作用下顺利进行, 并得到较高 的收率(74\% 99\%); 溴苯和烯烃反应时在同样催化剂 用量作用下必须添加四丁基澳化胺(TBAB)反应才能顺 利进行, 得到 $40 \% \sim 98 \%$ 的收率. 而氯苯由于活性较低, 在 $0.5 \mathrm{~mol} \%$ 催化剂作用下, 加入 $\mathrm{TBAB}$ 与对氯苯乙烯反 应也仅能得到 $40 \%$ 的收率, 而作者对其它取代氯苯的活 性和反应情况没有进行考察研究.

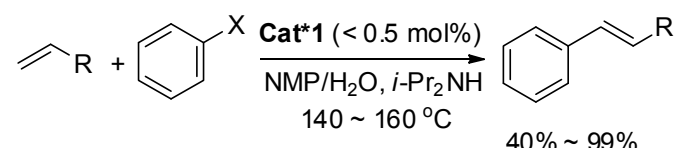

$\mathrm{R}=\mathrm{CO}_{2} \mathrm{Bu}-n, \mathrm{CO}_{2} \mathrm{Bu}-t, 4-\mathrm{ClC}_{6} \mathrm{H}_{4}$ $\mathrm{X}=\mathrm{I}, \mathrm{Br}, \mathrm{Cl}$<smiles></smiles>

2004 年, Liu 等 ${ }^{[18]}$ 报道了负载在纳米 MCM-41 介孔 材料上的联吡定 Pd 类络合物催化剂 Cat*3 催化的 Heck 偶联反应 (Eq. 2). 该催化剂是由配体 $\mathbf{L 3}$ 和钯盐 $\left(\mathrm{CH}_{3} \mathrm{CN}\right)_{2} \mathrm{PdCl}_{2}$ 络合形成的; 其中配体 $\mathbf{L 3}$ 中硅的结构则 是这种催化剂具有很好活性的关键. 当反应体系以 $\mathrm{Et}_{3} \mathrm{~N}$ 为碱, $\mathrm{NMP}$ 为溶剂时, 于 $100{ }^{\circ} \mathrm{C}$ 下反应 $96 \mathrm{~h}$, 碘苯 和对甲基碘苯在 $0.0001 \mathrm{~mol} \%$ 的催化剂用量下可以分别 和苯乙烯、丙烯酸甲酯及丙烯酸正丁酯反应, 并取得 $83 \% \sim 98 \%$ 的收率. 而溴代芳烃和烯烃反应时，需用
$\mathrm{Bu}_{3} \mathrm{~N}$ 代替 $\mathrm{Et}_{3} \mathrm{~N}$, 并适当增加催化剂 $\mathrm{Cat}^{* 3}$ 的用量, 在 $160{ }^{\circ} \mathrm{C}$ 下反应才能顺利进行. 吸电子基团取代的溴苯和 烯烃在 $0.0002 \mathrm{~mol} \%$ 的催化剂用量下反应, 收率可达到 $72 \%$ ～96\%; 而给电子基团取代的溴苯如对溴苯甲醚和 丙烯酸正丁酯反应，在 $0.01 \mathrm{~mol} \%$ 的催化剂作用下反应 也仅能取得 $12 \%$ 的收率. 该催化剂具有催化效率高和可 回收的特点，当反应结束后，反应体系经过离心和干燥， 即可回收催化剂，重复使用四次后，在相同的反应时间 内, 收率都可保持不变, 且反应 TON 高达 $10^{6}$, 这为达 到绿色化学的目的提供了一个可能.
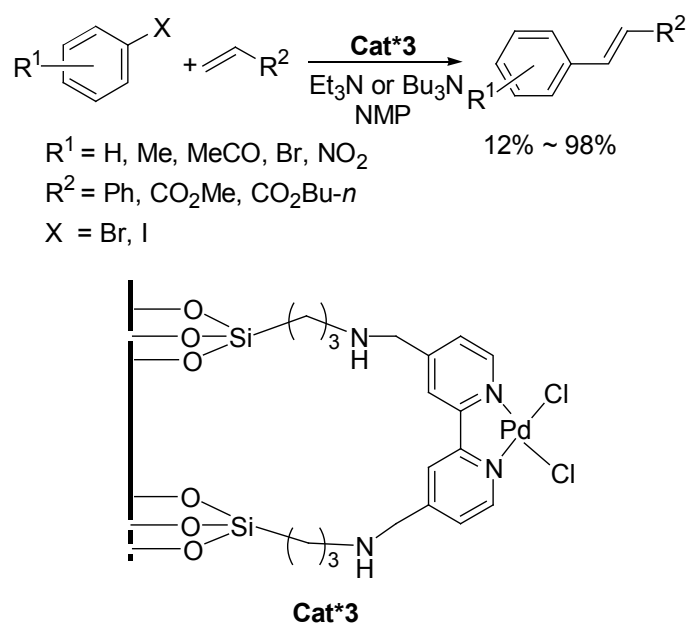

2005 年, Nájera 等 ${ }^{[19]}$ 又进一步深入研究了联吡啶钯 类催化剂 Cat*1 在 Heck 偶联反应中的应用. 通过实验 研究发现反应以水为溶剂，二异丙基胺 $\left(i-\mathrm{Pr}_{2} \mathrm{NH}\right)$ 为碱， $\mathrm{TBAB}$ 作相转移催化剂, 于 $100{ }^{\circ} \mathrm{C}$ 下, Cat*1 在低催化 剂用量下(小于 $0.5 \mathrm{~mol} \%$ ) 就可以很好地催化对乙酰基溴 苯和苯乙烯或丙烯酸叔丁酯的 Heck 偶联(Eq. 3). 催化 剂 Cat*1 在 TBAB 存在下可以在水相中形成更稳定的胶 体，极大地增加了底物转化率，可使吸电子基团取代的 
碘苯和澳苯在该催化体系下顺利地反应, 取得较高的收 率(78\% 99\%), 而给电子基团取代的碘代和溴代苯本 文没有叙述; 氯代芳烃在该反应条件下不能发生反应.

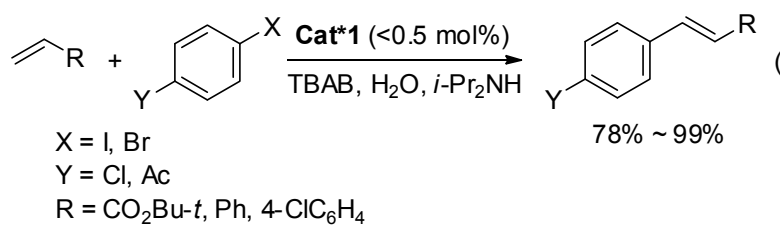

2010 年, Tsai 等 ${ }^{[20]}$ 报道了把在空气中稳定并且可重 复使用的 $\mathrm{Pd}\left(\mathrm{NH}_{3}\right)_{2} \mathrm{Cl}_{2} / \mathbf{L} \mathbf{4} / \mathrm{Bu}_{3} \mathrm{~N}$ 催化体系用于催化碘代 芳烃和烯烃在水溶液中的 Heck 偶联(Eq. 4). 反应条件 是以 $\mathrm{Pd}\left(\mathrm{NH}_{3}\right)_{2} \mathrm{Cl}_{2} / \mathbf{L} \mathbf{4}$ 作催化剂, $\mathrm{H}_{2} \mathrm{O}$ 作溶剂, $\mathrm{Bu}_{3} \mathrm{~N}$ 作碱, 温度为 $140{ }^{\circ} \mathrm{C}$ 于密封条件下反应. 研究发现对于该反 应，无机碱对反应没有促进作用，在有机碱存在下，可 得到较好的收率, 如在该催化体系下以 $\mathrm{Bu}_{3} \mathrm{~N}$ 为碱, 碘 苯和丙烯酸正丁酯的反应收率最高可到 $99 \%$. 底物广普 性研究表明一系列碘代芳烃和丙烯酸正丁基酯或乙基 酯在低催化剂用量 $(0.0001 \sim 0.01 \mathrm{~mol} \%)$ 下反应就可得到 中等到较好的收率 $(56 \% \sim 99 \%)$, 且反应的 TON 非常高, 可达到 $9.1 \times 10^{5}$. 而对于碘代芳烃和苯乙烯的偶联, 则 需要增加催化剂用量到 $1 \mathrm{~mol} \%$, 并以 $\mathrm{TBAB}$ 作为相转 移催化剂, 反应才能顺利进行, 取得 $68 \% \sim 93 \%$ 的收率. 由于水溶性配体 $\mathbf{L} \mathbf{4}$ 的作用, 催化剂 $\mathrm{Pd}\left(\mathrm{NH}_{3}\right)_{2} \mathrm{Cl}_{2}$ 在水溶 液中能够更高效地催化碘代芳烃的 Heck 偶联反应; 且 在反应结束后反应体系经过简单萃取, 产物溶于有机相 中, 催化剂溶于水相中继续使用, 这样很容易使催化剂 和产物分离, 有效地解决了贵金属的回收问题. 反应溶 液经过五次重复使用后, 在相同的反应时间内, 反应收 率从 99\%降低到 $90 \%$.

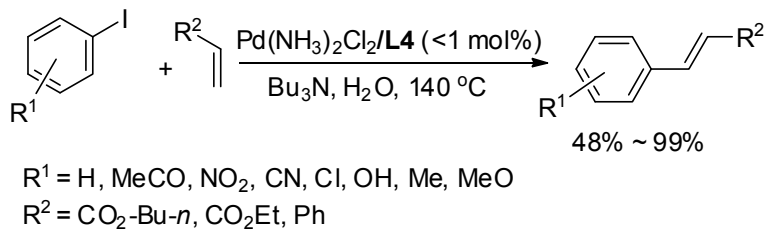

2013 年, Deshpande 等 ${ }^{[21]}$ 报道了采用 $\mathbf{L} 7 / \mathrm{PdCl}_{2}$ 作催 化剂催化的芳香烯烃和脂肪烯烃分别与卤代芳烃(I 和 Br)的 Heck 偶联(Eq. 5). 该反应体系以 TBAB 作相转移 催化剂, NMP 为溶剂, KOAc 为碱, 反应温度是 $150{ }^{\circ} \mathrm{C}$; 其中 TBAB 的加入可以提高反应速率. 反应广普性研究 表明: 芳香烯烃和脂肪烯烃均可与芳香碘苯很好地反 应, 并取得 $40 \% \sim 100 \%$ 的收率; 而芳香溴苯由于活性 降低和苯乙烯反应仅能得到 $45 \%$ ～54\%的收率, 而与脂 肪烯烃的反应未作考察.

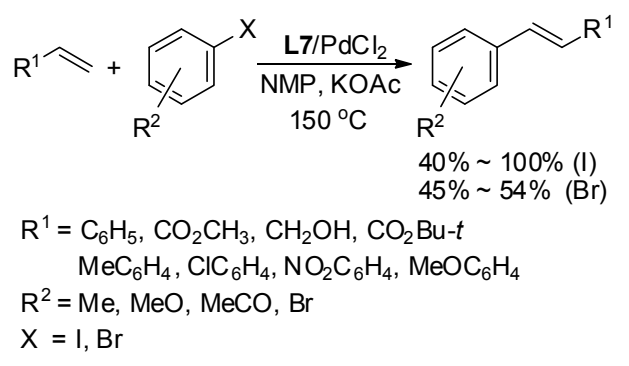

\subsubsection{Suzuki 偶联反应}

有机硼酸化合物与卤代芳烃在零价钯配合物催化 下发生交叉偶联的反应称为 Suzuki 偶联, 该反应由 Suzuki 在 1970 年首次报道. Suzuki 偶联是形成 C-C 键 最有效的方法之一, 具有对底物的选择性广、反应条件 温和、副产物少且产物易于处理等优点 ${ }^{[22,23]}$. 当前, Suzuki 偶联反应的研究重点之一是合成并筛选与金属 络合后能够在温和条件下高效催化卤代芳烃(特别是氯 代芳烃)反应的配体.

2003 年, Nájera 等 ${ }^{\left[{ }^{[7]}\right.}$ 又将其报道的联吡啶类钯催化 剂 Cat*1 用于催化卤代芳烃 $(\mathrm{Br}$ 和 $\mathrm{Cl})$ 与苯硼酸的 Suzuki 偶联中(Eq. 6). 该体系以 $\mathrm{K}_{2} \mathrm{CO}_{3}$ 为碱, 催化剂 Cat*1 在 $\mathrm{DMF}$ 与水的混合溶剂中于 $110{ }^{\circ} \mathrm{C}$ 下可以有效地催化 $\mathrm{N}, \mathrm{N}$-二甲基、乙酰基、氨基和羟基取代的澳代芳烃与苯 嗍酸的偶联, 并得到了较高的收率 $(75 \% \sim 99 \%)$, 而氯 代芳烃参与反应时必须添加 TBAB 作添加剂, 反应才能 顺利进行，取得 73\% 99\%的收率.

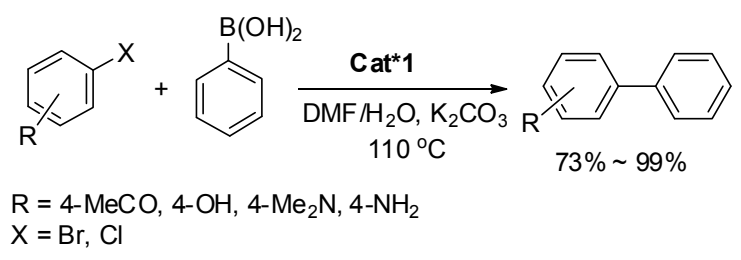

2004 年, Nájera 等 ${ }^{[24]}$ 又进一步报道了在水溶液中催 化剂 Cat*1 催化溴代芳烃和氯代芳烃与有机嗍酸的 Suzuki 偶联(Eq. 7). 该反应使用 $\mathrm{K}_{2} \mathrm{CO}_{3}$ 作碱, 于 $100{ }^{\circ} \mathrm{C}$ 下在水相中加入少量催化剂 Cat*1 $(0.002 \mathrm{~mol} \%)$ 就可使 一系列溴代芳烃和有机硼酸的偶联反应顺利进行, 取得 82\% 99\%的收率. 该催化体系对含有一系列空间位阻 大的溴代芳烃也显示出了很高的活性, 如 1,3-二甲基-2溴苯和苯嗍酸反应，可以取得 $83 \%$ 的收率. 而氯代芳烃 和烷基硼酸反应时由于活性较低, 需要增加催化剂用量 到 1.0 10 mol\%之间, 并加入 TBAB 作添加剂才可以使 反应顺利进行，取得 $69 \% \sim 100 \%$ 的收率.

2005 年, Nájera 等 ${ }^{[19]}$ 将其研发出的单体催化剂 Cat*1 和聚合物联吡啶钯类催化剂 Cat*4 应用于卤代芳 烃 $(\mathrm{Br}$ 和 $\mathrm{Cl})$ 和苯硼酸的 Suzuki 偶联反应中. 以 $\mathrm{K}_{2} \mathrm{CO}_{3}$ 


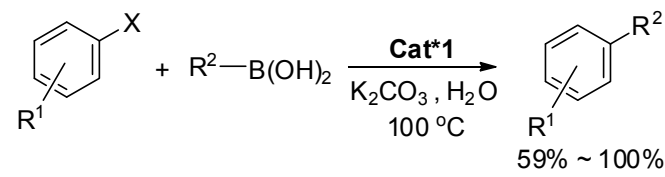

$\mathrm{R}^{1}=\mathrm{H}, \mathrm{Me}, \mathrm{MeO}, \mathrm{MeCO}, \mathrm{CN}, \mathrm{AcNH}, \mathrm{Me}_{2} \mathrm{~N}, \mathrm{CH}_{2} \mathrm{CO}_{2} \mathrm{H}$ $\mathrm{R}^{2}=\mathrm{C}_{6} \mathrm{H}_{5}, \mathrm{MeC}_{6} \mathrm{H}_{4}, \mathrm{C}_{4} \mathrm{H}_{3} \mathrm{~S}, \mathrm{FC}_{6} \mathrm{H}_{4}, \mathrm{Me}, n-\mathrm{Bu}$ $\mathrm{X}=\mathrm{Br}, \mathrm{Cl}$

为碱于 $100{ }^{\circ} \mathrm{C}$ 下, 在水溶剂中催化剂 Cat*1 和 Cat*4 都 可以很好地催化对乙酰基溴苯和对羟基溴苯分别与苯 嗍酸的 Suzuki 偶联反应(Eq. 8), 分别取得了 $86 \%, 99 \%$ 和 75\%, 99\%的收率. 而在该反应条件下，对乙酰基氯苯 和苯硼酸则不能顺利参与反应, 必须分别增加催化剂 Cat*1 和 Cat*4 的用量(4 mol\%)同时加入 TBAB 作添加 剂，反应才能顺利进行，分别取得 $99 \%$ 和 $88 \%$ 的收率， 而对其它氯代芳烃未作考察研究. 需要注意的是 Cat*4 是由聚合物配体 $\mathbf{L 5}$ 和 $\mathrm{Na}_{2} \mathrm{PdCl}_{4}$ 合成的, 虽然它和 Cat*1 在反应中表现出了相似的催化活性, 但是, Cat*4 具有可以重复回收使用的特性, Cat*4 在反应结束后通 过过滤重复使用三次后，反应活性有所降低，反应时间 需从 $0.5 \mathrm{~h}$ 增加到 $3 \mathrm{~h}$, 反应取得的收率才可保持不变.

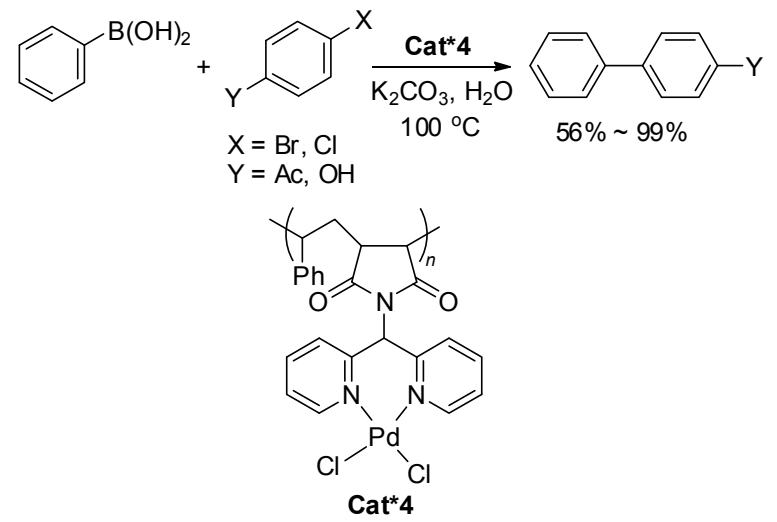

2006 年, Tsai 等 ${ }^{[25]}$ 报道了 $\mathrm{Pd}\left(\mathrm{NH}_{3}\right)_{2} \mathrm{Cl}_{2} / \mathbf{L} \mathbf{4}$ 在水相中 催化卤代芳烃 $(\mathrm{Br}$ 和 $\mathrm{Cl})$ 和芳基硼酸的 Suzuki 偶联反应 (Eq. 9). 以水为溶剂, $\mathrm{K}_{2} \mathrm{CO}_{3}$ 为碱, 于 $80{ }^{\circ} \mathrm{C}$ 下, 该催化 体系可以催化一系列溴代芳烃的 Suzuki 偶联反应, 吸电 子基团取代的溴代芳烃和各种芳基硼酸都可在少量催 化剂(0.001 0.1 mol\%)催化下顺利反应，并取得 97\% 99\%的收率. 由于在对位连有氨基和羟基的溴代芳烃比 溴苯在水中有更好的溶解性, 所以反应也能顺利进行, 可分别取得 86\% 99\%的收率; 而邻位取代的溴代芳烃 由于空间因素，反应不能很好地进行，如邻甲氧基溴苯 和苯硼酸反应时, 在将反应时间延长后, 也仅能取得 $40 \%$ 的收率. 而氯代芳烃由于活性较低, 需要将反应温 度增加到 $140{ }^{\circ} \mathrm{C}$, 催化剂用量增加到 $1 \mathrm{~mol} \%$, 并且加 入 $\mathrm{TBAB}$ 作添加剂, 吸电子基取代的氯代芳烃才能和各 种取代基取代的苯嗍酸顺利进行反应，取得 70\% 99\%
的收率; 氯苯和苯嗍酸反应时仅能得到 $50 \%$ 的收率; 而 给电子基取代的氯苯，作者只研究了对氯苯酚和对乙酰 基苯嗍酸的反应，由于对氯苯酚在水中有很好的溶解 性，反应取得了 $99 \%$ 的收率. 需要注意的是该水相体系 的特点是采用 TBAB 作添加剂, 无需惰性气体保护, 催 化剂用量少，后处理简单；反应完成后，产物可经过简 单萃取收集于有机相中，催化剂溶于水相中仍可重复使 用，循环使用五次后，反应活性有所降低，反应时间需 从 $0.5 \mathrm{~h}$ 增加到 $6 \mathrm{~h}$, 反应收率才能保持不变.

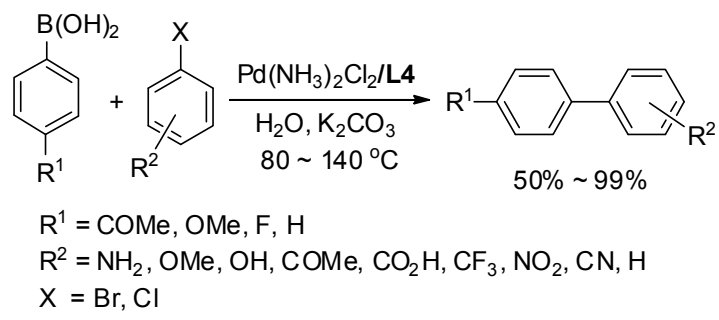

2010 年, Uozumi 等 ${ }^{[26]}$ 报道了由配体 $\mathbf{L 6}$ 与 $\mathrm{PdCl}_{2}$ 和 $\mathrm{CuNO}_{3} \cdot 3 \mathrm{H}_{2} \mathrm{O}$ 制备的在空气中稳定并且可重复使用的自 身负载的聚合物型催化剂 Cat*5, 并把它用于催化卤代 芳烃(I 和 Br)和芳基硼酸的 Suzuki 偶联反应中(Eq. 10). 该催化体系以水为溶剂, $\mathrm{Na}_{2} \mathrm{CO}_{3}$ 为碱, 于 $100{ }^{\circ} \mathrm{C}$ 下可以 有效地催化碘苯与芳基硼酸的偶联，并得到中等到较高 的收率 $(75 \% \sim 99 \%)$; 在相同的反应条件下溴苯也可与 芳基硼酸有效地进行反应，并取得了 76\% 94\%的收率. 该催化体系对含有一系列空间位阻大的苯硼酸也显示 了很高的活性，邻位和间位取代的苯嗍酸均可分别与碘 苯和溴苯进行反应，得到 $77 \%$ ～93\%的收率；1-荟砋酸 也可分别与碘苯和溴苯偶联，均可得到 $75 \%$ 的收率; 而 氯苯在该体系中则根本无法与苯硣酸发生反应。需要注 意的是催化剂 Cat*5 具有催化效率高、在空气中稳定和 可回收的特性，在重复使用五次后，催化剂仍保持了很 高的催化活性，在相同的反应时间内，反应取得的收率 基本保持不变.
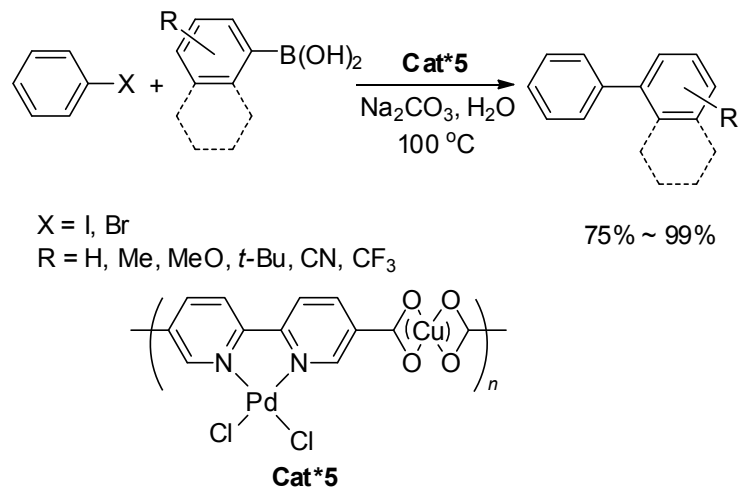

$75 \% \sim 99 \%$

2013 年, $\mathrm{Li}$ 等 ${ }^{[27]}$ 报道了以 $\mathrm{Pd} / \mathrm{Y}-\mathrm{MOF}$ 作催化剂催化 
卤代芳烃 $(\mathrm{I}, \mathrm{Br}$ 和 $\mathrm{Cl}$ ) 和对甲基苯嗍酸的 Suzuki 偶联反应 (Eq. 11). 该体系采用 $\mathrm{K}_{2} \mathrm{CO}_{3}$ 作碱, 水为溶剂。其中 $\mathrm{Pd} / \mathrm{Y}-\mathrm{MOF}$ 是由 $\mathrm{K}_{2} \mathrm{PdCl}_{4}, \mathrm{Y}\left(\mathrm{NO}_{3}\right)_{3} \cdot 6 \mathrm{H}_{2} \mathrm{O}$ 和配体 $\mathbf{L 6}$ 合成 的. 反应广普性研究表明吸电子基取代的碘苯如对硝基 碘苯可取得 96\%的收率; 而供电子基取代的碘苯如 4-叔 丁基碘苯仅能得到 5.5\%的收率, 其余的芳基碘可取得 46\% 96\%的收率，溴苯可取得 59\%的收率; 氯苯由于 活性较低，即使在反应中加入 TBAB，也仅能得到 $22 \%$ 的收率，而文中未对官能团取代的溴苯和氯苯参与的反 应进行考察. 需要注意的是该催化剂在重复使用 5 次后, 仍保持了很高的催化活性, 在相同的反应时间内, 反应 取得的收率没有显著降低.

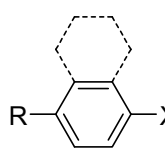<smiles>Cc1ccc(Br)cc1</smiles>
$\mathrm{K}_{2} \mathrm{CO}_{3}, \mathrm{H}_{2} \mathrm{O}$ $80^{\circ} \mathrm{C}$

$\mathrm{R}=\mathrm{H}, \mathrm{Me}, \mathrm{MeO}, \mathrm{NO}_{2}, t-\mathrm{Bu}$ $\mathrm{X}=\mathrm{I}, \mathrm{Br}, \mathrm{Cl}$

\subsubsection{Negishi 偶联反应}

1977 年, Negishi 等 ${ }^{[28,29]}$ 首次报道了在钯和镍催化作 用下有机锌与卤代芳烃的偶联反应. 有机锌试剂具有活 性高、制备简单、低毒的特性, 该反应在 $\mathrm{C}-\mathrm{C}$ 键的构 成中也具有非常重要的作用.

2013 年, Tsai 等 ${ }^{[30]}$ 又将负载在纳米 MCM-41 介孔材 料上的联吡啶钯类催化剂 $\mathbf{C a t} * \mathbf{3}$ 应用于溴代芳烃与有机 氯化锌的 Negishi 偶联反应中(Eq. 12). 他们发现采用 Cat*3/PPh 3 催化体系在 $\mathrm{THF}$ 溶剂中于 $70{ }^{\circ} \mathrm{C}$ 下就可以很 好地催化溴代芳烃和有机氯化锌的 Negishi 偶联, Pd 的 用量小于 $0.1 \mathrm{~mol} \%$, 而需要注意的是 $\mathrm{PPh}_{3}$ 在反应过程 中的作用至关重要, 若不加 $\mathrm{PPh}_{3}$ 则反应根本不能发生. 该催化体系可以催化一系列吸电子基团取代的芳烃或 杂芳烃的溴化物和苯基氯化锌反应，取得 $80 \%$ ～99\%的 收率; 而给电子基团取代的溴苯则不能与苯基氯化锌顺 利进行反应，仅取得 40\% 42\%的收率; 而连有烷基， 炔基和杂环的氯代锌试剂在增加催化剂的用量达到 1 $\mathrm{mol} \%$ 并增加反应时间后同样可以很好地和溴代芳烃进 行反应，取得 $64 \% \sim 99 \%$ 的收率.

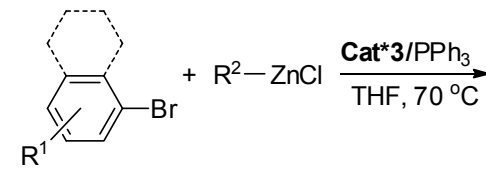

$\mathrm{R}^{1}=\mathrm{H}, \mathrm{CN}, \mathrm{CF}_{3}, \mathrm{CO}_{2} \mathrm{Me}, \mathrm{Cl}$ $\mathrm{R}^{2}=\mathrm{Me}, n-\mathrm{C}_{4} \mathrm{H}_{9}, \mathrm{C}_{6} \mathrm{H}_{5}, \mathrm{C}_{8} \mathrm{H}_{13}, \mathrm{MeC}_{6} \mathrm{H}_{4}, \mathrm{MeOC}_{6} \mathrm{H}_{4}, \mathrm{C}_{4} \mathrm{H}_{3} \mathrm{~S}$

\subsubsection{Hiyama 偶联反应}

Hiyama 等 ${ }^{[31]}$ 在 1988 年首次报道了在钯或镍催化下 芳基、烯基、烷基卤化物或拟卤(如三氟甲磺酸酯)类化 合物与有机硅烷之间的交叉偶联反应. 该反应具有原子 经济性高、对环境影响小、有机硅试剂容易储存、操作 简便、毒性低、反应条件比较温和、产率和选择性高以 及对其它官能团的耐受性较好等诸多优点.

2008 年, Tsai 等 ${ }^{[32}$ 报道了 $\mathrm{Pd}\left(\mathrm{NH}_{3}\right)_{2} \mathrm{Cl}_{2} / \mathbf{L} \mathbf{4}$ 水相催化 体系催化溴代芳烃的 Hiyama 偶联反应. 该体系以 $\mathrm{NaOH}$ 为碱, 于 $120{ }^{\circ} \mathrm{C}$ 下反应 $6 \mathrm{~h}, \mathrm{Pd}\left(\mathrm{NH}_{3}\right)_{2} \mathrm{Cl}_{2} / \mathbf{L} \mathbf{4}$ 可以 很好地催化溴代芳烃和三乙氧基芳基硅烷的 Hiyama 偶 联(Eq. 13)，反应中 Pd 的用量小于 $1 \mathrm{~mol} \%$. 该反应以对 溴苯甲醚和三乙氧基苯基硅烷的反应作标准反应进行 考察, 经实验发现配体 $\mathbf{L 4}$ 对增强 $\mathrm{Pd}\left(\mathrm{NH}_{3}\right)_{2} \mathrm{Cl}_{2}$ 的活性起 到了至关重要的作用, 如反应体系中不加入配体 $\mathbf{L 4}$, 则 反应不能顺利进行，仅能得到 $40 \%$ 的收率; 而有配体存 在时, 可以取得 $99 \%$ 的收率. 反应广普性研究表明连有 甲酰基、乙酰基和氯等吸电子基取代的溴代芳烃与三乙 氧基苯基硅烷可以在少量催化剂( $0.001 \sim 0.1 \mathrm{~mol} \%$ )作用 下很好地反应，取得 $95 \%$ \% 9 \%的收率; 而给电子或电 中性基团取代的溴代芳烃在 $0.1 \sim 1 \mathrm{~mol} \%$ 的催化剂作用 下也可以发生反应，但一系列底物仅能取得 $35 \%$ 75\% 的收率. 给电子和吸电子基团取代的三乙氧基苯基硅烷 对反应活性和收率几乎没有影响, 如对乙酰基溴苯分别 和对甲基、对甲氧基、对氟和对氯取代的三乙氧基芳基 硅烷进行反应，反应均可得到 $99 \%$ 的收率. 需要注意的 是, 该反应是在水相中进行的, 且没有加入任何添加剂, 如相转移催化剂 TBAB. 在反应完成后, 产物经过简单 萃取溶于有机相中, 溶有催化体系的水相仍可重复使用 四次，但反应活性有所降低，反应时间需从 $2 \mathrm{~h}$ 增加到 6 $\mathrm{h}$, 反应取得的收率从 $99 \%$ 降低到 $90 \%$.

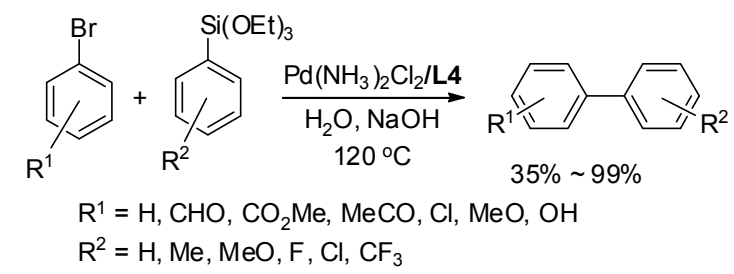

(13)

\subsubsection{Kumada-Corriu 偶联反应}

1972 年, Corriu 和 Kumada 等 ${ }^{[33,34]}$ 分别独立报道了 在钯或镍催化下格氏试剂和有机血化物的交叉偶联反 应. 该反应是有机反应中形成 $\mathrm{C}-\mathrm{C}$ 键的典型反应，也 是最早报道的交叉偶联反应之一, 且一直被应用于有机 合成中，后来被称作 Kumada-Corriu 偶联反应.

2007 年, Tsai 等 ${ }^{[35]}$ 又将负载在纳米 MCM-41 介孔材 料上的联吡啶钯类催化剂 Cat*3 用于催化卤代芳烃(I, 
Br)和有机澳化镁试剂的 Kumada-Corriu 反应(Eq. 14)中. 反应在 Cat*3 存在下于 $\mathrm{THF}$ 溶液中在 $50 \sim 60{ }^{\circ} \mathrm{C}$ 下进 行. 在这之前, 还没人报道将负载在有序介孔材料上的 钯催化剂用于 Kumada-Corriu 反应中. 反应广普性研究 表明碘苯和有机溴化镁格氏试剂在 $0.05 \mathrm{~mol} \%$ 的催化剂 用量下可以有效地进行反应，并取得 67\% 98\%的收率， 而最引人注意的是碘苯可以和乙烯基溴化镁反应生成 苯乙烯, 并取得了 $67 \%$ 的收率; 溴代芳烃和溴代噻吩由 于活性降低, 需要将反应温度增加到 $60{ }^{\circ} \mathrm{C}$, 催化剂用 量也要相应增加 $(0.05 \sim 0.2 \mathrm{~mol} \%)$, 同时还要加入 $\mathrm{PPh}_{3}$, 才能与芳基和噻吩基取代的溴化镁顺利进行反应, 取得 $47 \% \sim 94 \%$ 的收率. 其中有较大空间位阻的溴苯如 1,3,5-三甲基-2-溴苯可以和 4-甲氧基苯基溴化镁可有效 地反应, 并得到 $93 \%$ 的收率; 而氯苯由于活性较低反应 不能进行. 通过实验, 作者发现该催化剂经过三次回收 使用后，催化反应的活性有所降低，当反应时间从 $8 \mathrm{~h}$ 增加到 $24 \mathrm{~h}$ 后，反应取得的收率才可保持不变.

$$
\begin{aligned}
\mathrm{R}^{1}-\mathrm{X}+\mathrm{R}^{2}-\mathrm{MgBr} & \stackrel{\text { Cat*3 }(0.05 \sim 0.2 \mathrm{~mol} \%)}{\mathrm{THF}, 50 \sim 60^{\circ} \mathrm{C}} \begin{array}{c}
\mathrm{R}^{1}-\mathrm{R}^{2} \\
47 \% \sim 98 \%
\end{array} \\
\mathrm{R}^{1} & =\mathrm{C}_{6} \mathrm{H}_{5}, \mathrm{MeC}_{6} \mathrm{H}_{4}, \mathrm{MeOC}_{6} \mathrm{H}_{4}, \mathrm{ClC}_{6} \mathrm{H}_{4}, \mathrm{C}_{4} \mathrm{H}_{3} \mathrm{~S}, \mathrm{C}_{6} \mathrm{H}_{5} \mathrm{CH}_{2} \\
\mathrm{R}^{2} & =\mathrm{C}_{6} \mathrm{H}_{5}, \mathrm{MeOC}_{6} \mathrm{H}_{4}, \mathrm{C}_{4} \mathrm{H}_{3} \mathrm{~S}, \mathrm{C}_{2} \mathrm{H}_{3} \\
X & =\mathrm{I}, \mathrm{Br}
\end{aligned}
$$

\subsubsection{Sonogashira 偶联反应}

Sonogashira 偶联反应是炔烃和卤代芳烃的偶联反 应, 在反应体系中加入铜盐作为辅助催化剂可以有效地 提高反应收率，它是近年来合成有取代基炔烃的最有效 方法之一[36]

2003 年, Nájera 等 ${ }^{[17]}$ 又将其报道的联吡啶钯类催化 剂 Cat*1 用于催化卤代芳烃(I 和 Br)与各种炔(芳香和脂 肪族)的 Sonogashira 偶联中. 作者通过优化, 笁选出两 种催化体系都对该反应有很好的效果. 如当该反应以 NMP 为溶剂, 以四丁基己二酰胺(TBAA)为碱时, 无需 加入任何 $\mathrm{Cu}$ 盐作辅助催化剂, 于 $110{ }^{\circ} \mathrm{C}$ 下就可以使碘 代芳烃或溴代芳烃与苯乙炔顺利地发生偶联，取得 $69 \% \sim 97 \%$ 的收率; 而当反应在水相中进行时, 反应必 须加入 TBAB 作添加剂, 且以吡咯烷(pyrrolidine)为碱, 于 $100{ }^{\circ} \mathrm{C}$ 下可以使卤代芳烃( $\mathrm{I}$ 和 $\mathrm{Br}$ ) 和苯乙炔很好地反 应，取得 $89 \% \sim 99 \%$ 的收率(Eq. 15). 需要注意的是当炔 烃加入的适当过量时, 可以提高收率, 但是如果炔烃加 入的过多，则会增加副产物二炔烃的生成.

2005 年, Nájera 等 ${ }^{[19]}$ 又将其研发出的新型聚合联吡 啶钯类催化剂 Cat*4 应用于 Sonogashira 偶联反应中(Eq. 16). 该反应以吡咯烷(Pyrrolidine)为碱, 于 $100{ }^{\circ} \mathrm{C}$ 下, 催化剂 Cat*4 可以在水相中顺利地催化卤代芳烃(I 和

$$
\begin{aligned}
& \mathrm{R}^{1}=\mathrm{Cl}, \mathrm{MeO}, \mathrm{Me} \\
& \mathrm{R}^{2}=\mathrm{Ph}, n-\mathrm{C}_{4} \mathrm{H}_{9}, i-\mathrm{Pr}_{3} \mathrm{Si} \\
& \mathrm{X}=\mathrm{I}, \mathrm{Br}
\end{aligned}
$$

$\mathrm{Br}$ )与苯乙炔或三异丙基乙炔基硅烷的 Sonogashira 偶联, 催化剂的用量小于 $0.1 \mathrm{~mol} \%$. 在该水相体系中, TBAB 为相转移催化剂, 各种电子效应官能团取代的碘代或溴 代芳烃都可以分别与苯乙炔和三异丙基乙炔基硅烷反 应，并得到较好的收率( $87 \%$ \% $9 \%$ )；2-溴噻吩也可和苯 乙炔反应得到 $92 \%$ 的收率. 而需要注意的是，在相同的 条件下聚合物催化剂 Cat*4 催化反应取得的收率比催化 剂 Cat*1 催化反应取得的收率更高; 而且该聚合钯催化 剂 Cat*4 经过五次重复使用后，在相同的反应时间内， 反应取得的收率仍然可以比催化剂 Cat*1催化的反应取 得更高的收率.

$$
\begin{aligned}
& \mathrm{R}^{1}-\mathrm{X}+\mathrm{R}^{2}=\frac{\text { Cat }^{*} \mathbf{4}(<0.1 \mathrm{~mol} \%)}{\text { Pyrrolidine, TBAB, } \mathrm{H}_{2} \mathrm{O}} \mathrm{R}^{1}=\mathrm{R}^{2} \\
& \mathrm{X}=\mathrm{I} \% \sim 99 \% \\
& \mathrm{R}^{1}=4-\mathrm{ClC}_{6} \mathrm{H}_{4}, 4-\mathrm{MeOC}_{6} \mathrm{H}_{4}, 4-\mathrm{AcC}_{6} \mathrm{H}_{4}, \mathrm{C}_{4} \mathrm{H}_{3} \mathrm{~S} \\
& \mathrm{R}^{2}=\mathrm{Ph}, \mathrm{TIPS}
\end{aligned}
$$

2005 年, Nájera 等 ${ }^{[37]}$ 又进一步研究了催化剂 Cat*1 催化末端炔 (芳香和脂肪族) 与卤代芳烃( $\mathrm{I}$ 和 $\mathrm{Br}$ ) 的 Sonogashira 偶联(Eq. 17). 该反应以水为溶剂, 吡咯烷 (pyrrolidine)为碱, TBAB 作添加剂. TBAB 的加入可有效 地抑制炔烃的自偶联. 该催化体系可以催化一系列吸电 子或给电子基团取代的卤代芳烃( $\mathrm{I}$ 和 $\mathrm{Br}$ )与端基炔反应, 其中碘代芳烃和末端炔在 $0.001 \sim 0.1 \mathrm{~mol} \%$ 催化剂作用 下反应时可以取得 $69 \%$ ～100\%的收率; 而溴代芳烃和 末端炔在 $0.2 \sim 0.5 \mathrm{~mol} \%$ 催化剂用量作用下可以取得 66\% 96\%的收率. 烷基炔或三异丙基乙炔基硅烷分别 与对氯和对甲氧基取代的碘苯反应时亦可在 $0.1 \sim 0.2$ $\mathrm{mol} \%$ 的催化剂作用下顺利反应取得 $55 \%$ ～89\%的收率; 而它们分别与对氯溴苯反应时，可以取得 $75 \%$ 和 $87 \%$ 的 收率，关于其它溴代芳烃未作考察研究.

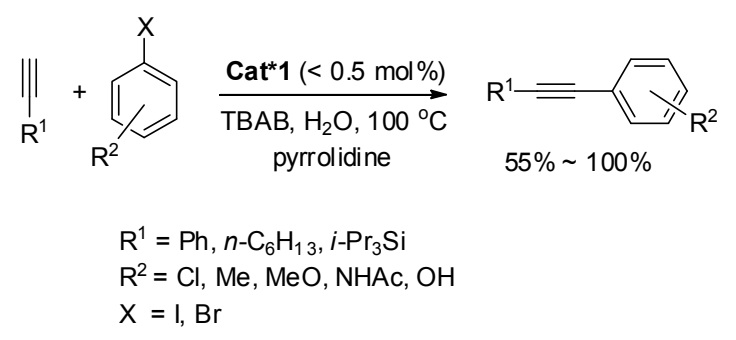

2010 年, Tsai 等 ${ }^{[38]}$ 又将其研发的纳米 MCM-41-Pd 
催化剂 $\mathbf{C a t}$ *3 应用于催化芳环和杂芳环卤化物(I 和 Br) 与末端炔的 Sonogashira 偶联反应中(Eq. 18). 该研究以 碘苯和苯乙炔的反应作标准反应进行优化篮选, 得出最 优条件为: $\mathrm{CuI}$ 作辅助催化剂, 以 $\mathrm{Et}_{3} \mathrm{~N}$ 为碱和溶剂, 并 需在反应体系中加入 $\mathrm{PPh}_{3}$. 需要注意的是 $\mathrm{PPh}_{3}$ 的加入 可增强催化剂 Cat*3 的催化活性, 若不加 $\mathrm{PPh}_{3}$ 则碘苯和 苯乙炔的反应仅能得到 $38 \%$ 的收率. 反应广普性研究表 明在 $50{ }^{\circ} \mathrm{C}$ 下, 只用少量催化剂 $(0.01 \sim 0.1 \mathrm{~mol} \%)$ 就可以 有效地催化一系列碘代芳烃与苯乙炔的偶联, 并且取得 了 $87 \%$ 99\%的收率. 溴代芳烃由于活性较低, 需提高 反应温度, 这时需将溶剂由 $\mathrm{Et}_{3} \mathrm{~N}$ 变为甲基吡咯烷酮 (NMP), 反应在 $90{ }^{\circ} \mathrm{C}$ 才能够顺利进行; 溴苯与苯乙炔 反应得到 56\%的收率; 吸电子基团取代的溴苯如乙酰 基、氧基与硝基取代的溴苯和苯乙炔反应能够取得 93\% 99\%的收率; 给电子基团取代的溴苯文中仅考察 了对甲氧基溴苯与苯乙炔的反应, 得到 40\%的收率. 溴 取代的噻吩和吡啶杂环也适用于该催化体系, 但需要注 意的是邻位取代的杂芳环溴化物比间位取代的溴化物 取得更高的收率，如 2-溴噻吩和苯乙炔反应能取得 71\% 的收率, 而3-澳噻吩和苯乙炔反应则只能取得 $36 \%$ 的收 率. 炔醇如炔丙醇、炔丁醇和炔戊醇也是很好的反应底 物, 在该反应体系下, 炔醇和碘代芳烃反应可以取得 41\% 94\%的收率; 炔醇也可以和吸电子基取代的溴苯 有效地发生反应, 并取得 45\% 98\%的收率. 但是炔醇 和杂环澳化物反应时, 不同的炔醇的活性表现出了极大 的不同; 如炔戊醇和溴代噻吩可以很好地反应, 并取得 59\% 99\%的收率; 而炔丙醇和溴代噻吩则不能顺利进 行反应，仅能得到 $8 \% \sim 18 \%$ 的收率.

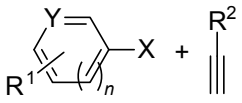

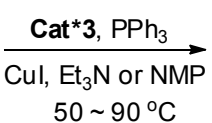

$\mathrm{X}=\mathrm{I}, \mathrm{Br}$

$\mathrm{R}^{1}=\mathrm{H}, \mathrm{MeO}, \mathrm{CN}, \mathrm{NO}_{2}, \mathrm{Cl}, \mathrm{MeCO}$

$\mathrm{R}^{2}=\mathrm{Ph}, \mathrm{C}\left(\mathrm{CH}_{3}\right)_{2} \mathrm{OH}, \mathrm{CH}_{2} \mathrm{OH}, \mathrm{CH}_{2} \mathrm{CH}_{2} \mathrm{OH}$

$n=1, \mathrm{Y}=\mathrm{CH}, \mathrm{NH} ; n=0, \mathrm{Y}=\mathrm{S}$

2012年, Tsai 等 ${ }^{[39]}$ 首次报道了在水相体系中 $\mathrm{Fe}$ 催化 碘代芳烃和芳基炔烃发生的 Sonogashira 偶联, 该反应 使用 $\mathrm{FeCl}_{3} \cdot 6 \mathrm{H}_{2} \mathrm{O} / \mathbf{L} 4$ 作催化剂, $\mathrm{KOH}$ 作碱, 于 $140{ }^{\circ} \mathrm{C}$ 下 可有效催化一系列碘代芳烃与芳香炔的偶联反应(Eq. $19)$, 以此构建 $\mathrm{C}(\mathrm{sp})-\mathrm{C}\left(\mathrm{sp}^{2}\right)$ 键, 反应收率最高可达 99\%. 需要注意的是配体 L4 对该催化体系至关重要, 可 以使反应在低催化剂量下顺利进行; 若不加配体 $\mathbf{L 4}$, 则反应根本无法发生，这可能是由于配体 $\mathbf{L} 4$ 上的氨基 充当了相转移催化剂的原因. 为了提高反应的收率, 作 者采用锌粉作还原剂, 因为据文献报道锌粉在铁离子催 化体系中能促进三炔烃类化合物(triynes)的分子内聚合 成环. 在该反应体系中若不加入锌粉, 则碘苯和苯乙炔 反应仅能取得 $46 \%$ 的收率. 在该反应中空间位阻大的邻 位取代碘代芳烃如邻甲基碘苯和 4-苯基-3-丁炔反应, 可取得 77\%的收率; 而邻位有取代基的芳基炔则不能顺 利反应，只能得到 $33 \% \sim 57 \%$ 的收率. 需要注意的是在 对位连有强吸电子基团的碘苯则不能顺利进行，且有大 量副产物生成, 这可能是由于底物的 $\mathrm{C}-\mathrm{I}$ 键优先被锌 粉还原造成的. 该 $\mathrm{FeCl}_{3} \cdot 6 \mathrm{H}_{2} \mathrm{O} / \mathbf{L} 4$ 催化体系无需有机溶 剂, 无需 $\mathrm{Cu}$ 盐作辅助催化剂, 无需 $\mathrm{N}_{2}$ 保护, 就可以直 接催化磑代芳烃的反应, 缺点是反应温度比较高, 且该 体系无法催化溴代芳烃的偶联.

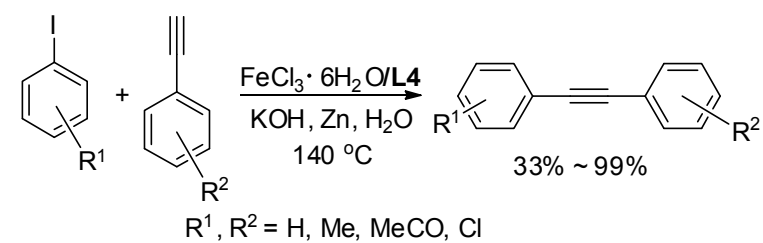

2013 年, $\mathrm{Li}$ 等 ${ }^{[27]}$ 又用 $\mathrm{Pd} / \mathrm{Y}-\mathrm{MOF}$ 作催化剂, 二氮杂 二环 $(\mathrm{DBU})$ 作碱, 于 $90{ }^{\circ} \mathrm{C}$ 下在水相中实现了对位官能 团取代的芳基碘与芳基炔烃的 Sonogashira 偶联(Eq. 20). 反应广普性研究表明除 4-叔丁基碘苯和苯乙炔反应仅 能得到 7.5\%的收率外(由于空间结构因素), 其它无论是 供电子基还是吸电子基取代的芳基碘和芳基炔反应均 可得到 79\% 99\%的收率. 需注意的是该催化剂在相同 的反应时间内，重复使用 3 次反应收率没有明显的降低.

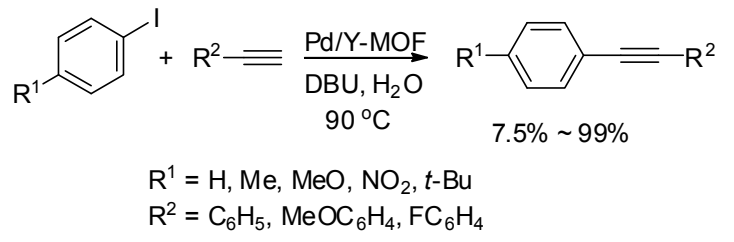

\subsubsection{Homocoupling 反应}

2006 年, $\mathrm{Fu}$ 等 ${ }^{[40]}$ 用 $\mathbf{C a t} * \mathbf{6}\left[\mathrm{Fe}(\mathrm{acac})_{3}-\mathrm{Al}(i-\mathrm{Bu})_{3}-\mathbf{L} 7\right]$ 作催化剂, 在氮气保护下实现了丙烯腈和苯乙烯的聚合 (Eq. 21). 通过对反应条件的优化篎选，作者发现当反应 体系以苯甲醚作溶剂, Cat*6 作催化剂, 单体丙烯腈与 苯乙烯物质的量之比为 $1: 1$ 时, 在 $80{ }^{\circ} \mathrm{C}$ 下反应 $10 \mathrm{~h}$ 可得到高交替度共聚物且收率最高 $(86.3 \%)$.

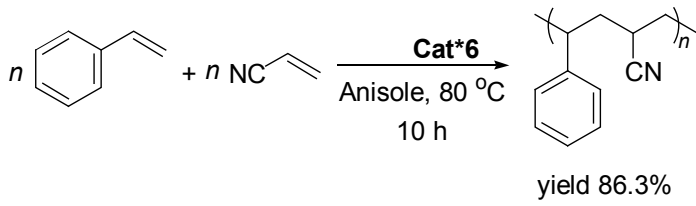

2007 年, Tsai 等 ${ }^{[41}$ 报道了 $[\mathrm{Rh}(\mathrm{cod}) \mathrm{Cl}]_{2} / \mathbf{L} \mathbf{4}$ 体系催化 
苯乙炔的聚合反应. 该催化剂的催化活性很高, 可以使 反应在水相中于室温下在较短的时间内 (30 min)顺利进 行, 得到了较高收率的具有高分子质量和顺式结构的聚 合物(Eq. 22). 作者对配体 L4 和 L7 在水相中的作用进 行了比较, 发现在水相中 $\mathbf{L} \mathbf{4}$ 比 $\mathbf{L 7}$ 具有更好的催化效 果, 且该催化体系经过重复使用后，仍具有很高的活性. 甲氧基、甲基、甲酸酯基、甲酸基和氟基取代的苯乙炔 均可进行聚合, 并得到 50\% 99\%的收率. 需要注意的 是合成聚合物顺式结构的含量都很高，可以达到 $92 \%$ $99 \%$.

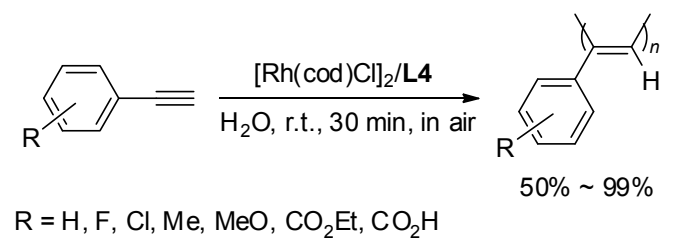

2009 年, Tsai 等 ${ }^{[42]}$ 首次报道了在水相中钯和铜催化 末端炔烃的自偶联反应(Eq. 23), 其反应条件是以 $\mathrm{Pd}\left(\mathrm{NH}_{3}\right)_{2} \mathrm{Cl}_{2} / \mathbf{L} 4$ 作催化剂, $\mathrm{CuI}$ 为辅助催化剂, $\mathrm{Et}_{3} \mathrm{~N}$ 为碱, $\mathrm{TBAB}$ 为添加剂, 反应温度为 $25{ }^{\circ} \mathrm{C}$. 在该催化体系的 作用下，间位和对位连有取代基的芳香族底物都可顺利 反应，取得 $82 \%$ ～99\%的收率，而邻位有取代基的底物 如邻甲基苯乙炔不能很好地反应，仅得到 43\%的反应收 率; 脂肪族底物则必须在有氧化剂 $\mathrm{I}_{2}$ 的存在下反应才可 以顺利进行(Eq. 24), 取得 49\% 99\%的收率; 氧化剂 $I_{2}$ 的添加不仅可以减少催化剂用量, 也可以极大地缩短反 应时间. 需注意的是该催化体系在水中有很好的稳定 性, 且可以在空气中保存; 反应结束后, 产物经萃取分 离进入有机相, 溶有催化剂的水相可以重复使用, 催化 剂经过四次使用后，在相同的反应时间内催化剂催化反 应取得的收率从 99\%降低到 $81 \%$.

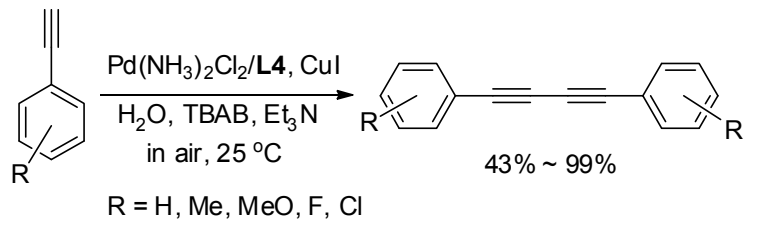

$$
\begin{aligned}
& \left.\mathrm{Pd}\left(\mathrm{NH}_{3}\right)_{2} \mathrm{Cl}_{2} / \mathrm{L} 4 \text { (0.0001 } 1 \mathrm{~mol} \%\right) \\
& \mathrm{R}=\frac{\mathrm{Cul}(1 \mathrm{~mol} \%), \mathrm{I}_{2} \text { (1 equiv.) }}{\mathrm{H}_{2} \mathrm{O}, \mathrm{TBAB}, \mathrm{Et}_{3} \mathrm{~N} \text {, in air, } 25^{\circ} \mathrm{C}} \mathrm{R} \underset{\overline{49 \%} \sim 99 \%}{=} \mathrm{R} \\
& \mathrm{R}=\mathrm{C}_{6} \mathrm{H}_{13}, \mathrm{C}_{10} \mathrm{H}_{21}, \mathrm{C}_{6} \mathrm{H}_{11}, \mathrm{C}_{6} \mathrm{H}_{5} \mathrm{OCH}_{2}, \mathrm{C}_{3} \mathrm{H}_{7} \mathrm{O}
\end{aligned}
$$

2011 年, $\mathrm{Tsai}$ 等 ${ }^{[43]}$ 报道了 $\mathrm{CuSO}_{4} \cdot 5 \mathrm{H}_{2} \mathrm{O} / \mathbf{L} 4$ 体系催化 一系列末端炔的自偶联(Eq. 25). 该反应采用 $\mathrm{CuSO}_{4}$ • $5 \mathrm{H}_{2} \mathrm{O} / \mathbf{L} \mathbf{4}$ 作催化剂, 以水为溶剂, $\mathrm{KOAc}$ 为碱, $\mathrm{I}_{2}$ 作氧化 剂, 在 $120{ }^{\circ} \mathrm{C}$ 下进行, 当反应底物为一系列芳基末端炔
时，对位和间位连有取代基的苯乙炔可得到 83\% 93\% 的收率; 而邻位取代的炔烃由于空间位阻的原因不能很 好地进行偶联，仅能得到 $63 \%$ ～72\%的收率. 而脂肪族 烷基取代的炔烃由于其弱酸性, 需要在反应中加入 TBAB，反应才能顺利进行(Eq. 26)，取得 50\% 90\%的 收率. 需要注意的是该催化剂易回收, 经过四次重复使 用后，在相同的时间内该催化剂催化反应取得的收率从 $99 \%$ 降低为 $71 \%$.

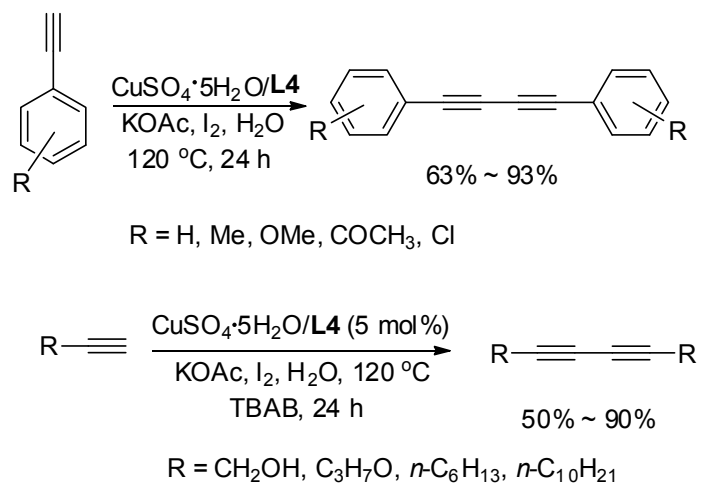

2012 年, Yamamoto 等 ${ }^{[44]}$ 报道应用 $\mathrm{NiCl}_{2} / \mathbf{L} 7 / \mathrm{Mg}$ 催 化体系, 可有效催化卤代芳烃 $(\mathrm{Br}$ 和 $\mathrm{Cl})$ 的脱卤自偶联反 应(Eq. 27), 以此构建 $\mathrm{C}-\mathrm{C}$ 键. 该反应以 $\mathrm{DMF}$ 为溶剂, 在反应体系中加入 $\mathrm{Mg}$ 来还原 $\mathrm{NiCl}_{2} / \mathbf{L} 7$ 催化体系, 从而 生成 $\mathrm{Ni}^{0} / \mathbf{L} 7$ 中间产物, 它可有效地促进底物的偶联. 作 者将该反应应用于含有单卤素和双卤素有机化合物的 高分子缩聚反应中，并得到了一系列的高分子聚合物. 溴代芳烃聚合可以取得 25\% 90\%的收率. 需要注意的 是当底物连有羰基时如对乙酰基溴苯虽然也能发生反 应，但只能得到 30\%的收率; 而苠基溴和 2-溴乙基苯也 仅能分别得到 $40 \%$ 和 $25 \%$ 的收率. 这是由于促进底物进 行 $\mathrm{C}-\mathrm{C}$ 偶联的 $\mathrm{Ni}^{0}$ 是通过还原 $\mathrm{NiCl}_{2} / \mathbf{L} 7$ 得到的, 而 $\mathrm{Ni}$ 与烷基和 $\mathrm{Ni}$ 与芳基(连有羰基)的连接键都有很高的稳 定性，从而抑制了含有羰基基团底物偶联的顺利进行. 而氯苯由于活性较低在相同条件下仅能得到 $65 \%$ 的收 率.

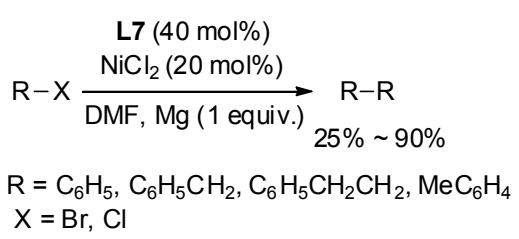

1.1 .8 其它

2009 年, Tsai 等 ${ }^{[45]}$ 又将负载在纳米 MCM-41 介孔材 料上的联吡啶钯类催化剂 Cat*3 应用于催化芳香和脂肪 族甲酰氯与三苯基铋的偶联反应中(Eq. 28). 反应采用 有机碱 $\mathrm{Et}_{3} \mathrm{~N}$ 作碱, $\mathrm{THF}$ 作溶剂, 于 $60{ }^{\circ} \mathrm{C}$ 下进行. 在该 
反应中，一分子三苯基铋可以和两分子的芳香或脂肪族 甲酰氯完全反应, 极大地提高了原子效率. 而需要注意 的是 $\mathrm{PPh}_{3}$ 的加入是非常关键的, 作者在以前的文章中 就介绍了它可使 $\mathrm{Pd}^{0}$ 在和有机卤化物进行氧化加成前更 稳定; 若不加 $\mathrm{PPh}_{3}$ 则苯甲酰氯和三苯基铋反应仅能取 得 5\%的收率. 该催化体系可以很好地催化甲基、氯、 溴和甲氧基等基团取代的芳环或杂芳环甲酰氯与三苯 基铋的偶联, 来合成各种芳基酮并得到 61\% 99\%的收 率; 当催化剂用量从 $1 \mathrm{~mol} \%$ 降到 $0.2 \mathrm{~mol} \%$ 时反应仍可 得到 $60 \% \sim 80 \%$ 的收率. 除此之外, 对位含有供电子或 吸电子基团的苯甲酰氯具有相似的活性, 可能是在均相 条件下，电子效应对该反应具有很小的影响. 而烷基甲 酰氯则无法顺利进行, 这是由于 $\mathrm{Et}_{3} \mathrm{~N}$ 可以和直链的脂 肪族酰氯进行 $[2+2]$ 环加成, 用二异丙基乙胺代替三乙 胺, 则可以有效地避免此副反应的发生, 有效地合成脂 肪族酮类.

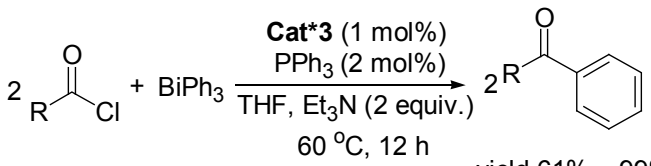

$$
\begin{aligned}
& \mathrm{R}=\mathrm{C}_{6} \mathrm{H}_{5}, \mathrm{ClC}_{6} \mathrm{H}_{4}, \mathrm{BrC}_{6} \mathrm{H}_{4}, \mathrm{MeC}_{6} \mathrm{H}_{4} \text {, } \\
& \mathrm{MeOC}_{6} \mathrm{H}_{4}, \mathrm{C}_{4} \mathrm{H}_{3} \mathrm{O}, \mathrm{C}_{4} \mathrm{H}_{3} \mathrm{~S}, n-\mathrm{C}_{5} \mathrm{H}_{11}
\end{aligned}
$$

2009 年, Tsai 等 ${ }^{[46]}$ 又将负载在纳米 MCM-41 介孔材 料上的联吡啶 Pd 催化剂 Cat*3 应用到有机甲酰氯(芳香 和脂肪)和末端炔的 $\mathrm{C}-\mathrm{C}$ 偶联反应中(Eq. 29). 反应采 用 $\mathrm{Ca} * * 3 / \mathrm{CuI}$ 催化体系在 $50{ }^{\circ} \mathrm{C}$ 下可以有效地催化芳基, 杂芳基和脂肪甲酰氯与末端炔的偶联, 且 $\mathrm{Pd}$ 的用量很 小 $(0.002 \sim 0.1 \mathrm{~mol} \%)$; 但此体系需要加入 $\mathrm{CuI}$ 作辅助催 化剂和 $\mathrm{PPh}_{3}$ 作添加剂. 该催化体系以 $\mathrm{Et}_{3} \mathrm{~N}$ 为碱, 这是 由于有机碱比无机碱在有机溶剂中有更好的溶解性, 反 应更易发生. 反应广普性研究表明芳基和杂芳环甲酰氯 都可以和芳香末端炔有效反应, 并取得 74\% 93\%的收 率; 但是脂肪甲酰氯反应时为避免底物和 $\mathrm{Et}_{3} \mathrm{~N}$ 反应, 需 用二异丙基乙胺(Diisopropylethylamine)代替 $\mathrm{Et}_{3} \mathrm{~N}$; 同时 由于活性问题需要增加催化剂用量到 $0.1 \mathrm{~mol} \%$, 烷基炔 与芳香或脂肪甲酰氯就可顺利偶联取得 $83 \% \sim 98 \%$ 的收 率.

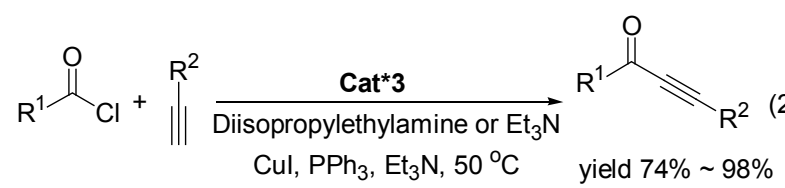

$$
\mathrm{R}^{1}=\text { aryl, heteroaryl, alkyl; } \mathrm{R}^{2}=\text { aryl, alkyl alkenyl }
$$

2012 年, Nishihara 等 ${ }^{[47]}$ 用 $\mathbf{L} 7 / \mathrm{PdCl}_{2}$ 作催化剂, 同时 加入 BrettPhos 作配体, $\mathrm{CuCl}$ 作辅助催化剂, DMF 作溶剂
的条件下实现了三甲基炔基硅烷分别与对甲基苯磺酯 和甲磺酸酯的交叉偶联(Eqs. 30，31). 反应的广普性研 究表明带有供电子基和吸电子基的对甲基苯磺酸芳基 酯均可与各种三甲基炔基硅烷反应并取得 31\% 84\%的 收率; 而需要注意的是三甲基-2-乙炔噻吩基硅烷和对 甲基苯磺酸苯酯反应仅能得到 $28 \%$ 的收率. 甲磺酸芳基 酯由于活性较低, 无论是带有供电子基还是吸电子基的 甲磺酸芳基酯都仅能得到 $21 \% \sim 41 \%$ 的收率.

$$
\begin{aligned}
& \text { L7/PdCl } \\
& \mathrm{R}^{1}=\mathrm{SiMe}_{3}+\mathrm{TsO}-\mathrm{R}^{2} \frac{\text { BrettPhos, CuCl }}{\mathrm{DMF}, 120^{\circ} \mathrm{C}, 24 \mathrm{~h}} \mathrm{R}^{1}=\mathrm{R}^{2} \text { (30) } \\
& \mathrm{R}^{1}=\mathrm{C}_{6} \mathrm{H}_{5}, \mathrm{MeOC}_{6} \mathrm{H}_{4}, \mathrm{CF}_{3} \mathrm{C}_{6} \mathrm{H}_{4}, \\
& \mathrm{R}^{2}=\mathrm{C}_{6} \mathrm{H}_{5}, \mathrm{FC}_{6} \mathrm{H}_{4}, \mathrm{MeOC}_{6} \mathrm{H}_{4}, \mathrm{CF}_{3} \mathrm{C}_{6} \mathrm{H}_{4}, \mathrm{MeCOC}_{6} \mathrm{H}_{4} \\
& \mathrm{R}^{1}=\mathrm{SiMe}_{3}+\mathrm{MsO}-\mathrm{R}^{2} \frac{\underset{\mathrm{BrettPhos}, \mathrm{CuCl}}{\mathrm{L} / \mathrm{PdCl}_{2}}}{\mathrm{DMF}, 120^{\circ} \mathrm{C}, 24 \mathrm{~h}} \mathrm{R}^{1}=\mathrm{R}^{2} \\
& \mathrm{R}^{1}=\mathrm{C}_{6} \mathrm{H}_{5}, \mathrm{MeOC}_{6} \mathrm{H}_{4} ; \mathrm{R}^{2}=\mathrm{C}_{6} \mathrm{H}_{5}, \mathrm{MeOC}_{6} \mathrm{H}_{4}, \mathrm{CNC}_{6} \mathrm{H}_{4}
\end{aligned}
$$
Cat*8 $\left[\operatorname{Ir}(\mathrm{ppy})_{2}(\mathrm{dtb}-\mathbf{L} 7)\right] \mathrm{PF}_{6}$ 作催化剂, 乙腈为溶剂, 在 可见光照射的条件下实现了 $N$-苯基四氢异喹啉和 $\alpha, \beta$ 不饱和羰基化合物的偶联(Eqs. 32, 33). 反应广普性研 究表明无论含有供电子基还是吸电子基的 $\alpha, \beta$-不饱和羰 基化合物在 Cat*7 催化作用下仅取得中等左右的收率 (43\% 58\%); 而在 Cat*8 的催化作用下可以取得中等 到较好的收率 $(50 \% \sim 93 \%)$.
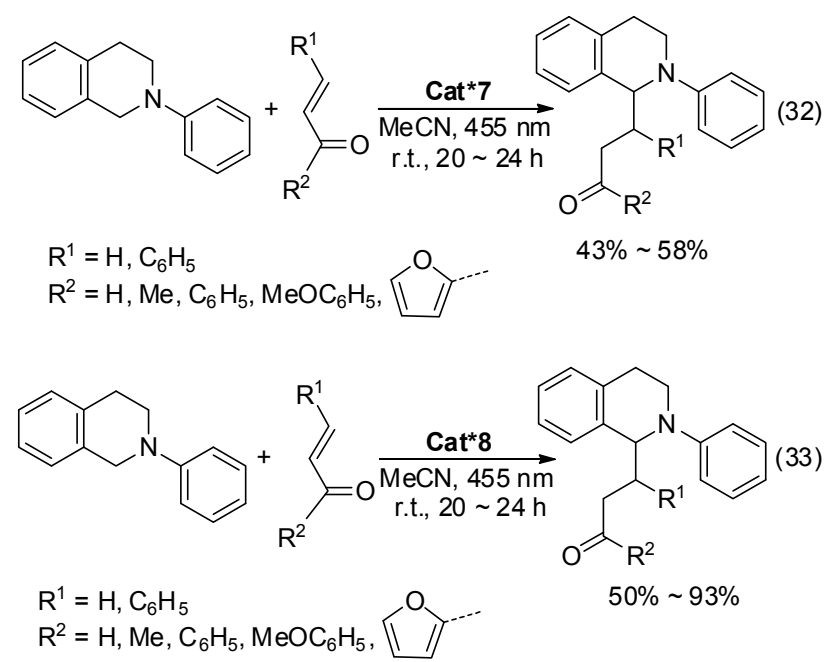

2012 年, Larhed 等 ${ }^{[49]}$ 报道了基于 $\mathrm{Pd}\left(\mathrm{O}_{2} \mathrm{CCF}_{3}\right)_{2} / \mathbf{L 8} /$ TFA 催化体系催化有机三氟硼酸钾与 1-哌啶羰腈的 CC 偶联反应(Eq. 34). 作者通过对各种联吡啶类配体的 笁选发现 $\mathbf{L 8}$ 对该反应有很好的促进作用. 该催化体系 以 TFA 为酸, 甲醇为溶剂, 于 $120{ }^{\circ} \mathrm{C}$ 下在微波条件下可 
以催化一系列给电子基团取代的杂芳环或芳环三氟硼 酸钾的偶联反应，并取得 $66 \% \sim 86 \%$ 的收率; 而吸电子 基团取代的芳基嗍酸钾如溴取代和乙酰基取代的苯基 三氟嗍酸钾由于较低的插入速率不能顺利地参与反应, 并且反应后副产物较多, 仅能得到小于 $37 \%$ 的收率. 需 要注意的是, TFA 在反应中起到重要作用, 若不加入 TFA 则反应根本无法进行.

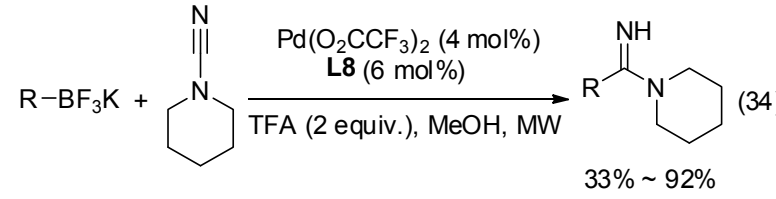

$\mathrm{R}=\mathrm{C}_{6} \mathrm{H}_{5}, \mathrm{MeOC}_{6} \mathrm{H}_{4}, \mathrm{MeC}_{6} \mathrm{H}_{4}, t-\mathrm{BuC}_{6} \mathrm{H}_{4}$

2012 年, Akita 等 ${ }^{[50]}$ 报道了以 $\left[\mathrm{Ru}(\mathbf{L} 7)_{3}\right]\left(\mathrm{PF}_{6}\right)_{2}$ 作催化 剂在可见光照射下烯胺与烯醇硅醚的氧化偶联反应(Eq. 35). 该反应以 $\mathrm{LiBF}_{4}$ 为 Lewis 酸, 2,5-二甲基苯醌为电子 吸收体, MS- $4 \AA$ 为添加剂, 乙腈为溶剂, 在室温下反应. 反应广普性研究表明带有供电子基的芳基烯醇硅醚和 芳香杂环烯醇硅醚与各种烯胺反应可得到 55\% 69\%的 收率; 而吸电子基取代的芳基烯醇硅醚参与反应时仅能 得到 33\%以下的收率，其中 4-硝基苯基烯醇硅醚根本不 能参与反应
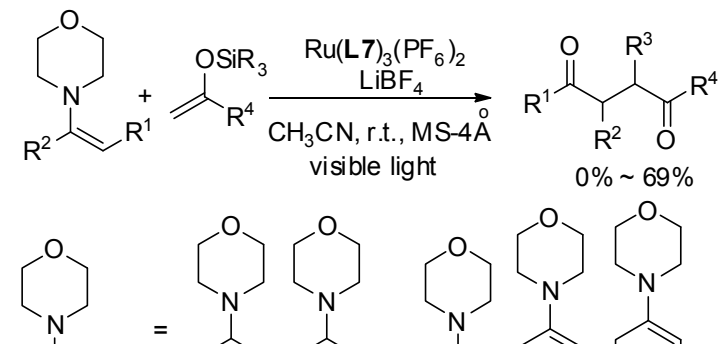<smiles>[R]C=C([R])N(C)C</smiles><smiles>CC=C(CC)N1CCOCC1</smiles><smiles>C=C(N1CCOCC1)C(C)(C)C</smiles><smiles>CC1CC=C(N2CCOCC2)CC1</smiles><smiles>C1=C(N2CCOCC2)CCC2(O1)OCCO2</smiles>

$\mathrm{R}^{3}=\mathrm{Me}, t-\mathrm{Bu}$

$\mathrm{R}^{4}=\mathrm{C}_{6} \mathrm{H}_{5}, \mathrm{CH}_{3} \mathrm{OC}_{6} \mathrm{H}_{4}, \mathrm{FC}_{6} \mathrm{H}_{4}, \mathrm{NO}_{2} \mathrm{C}_{6} \mathrm{H}_{4}$, furyl, thienyl

2013 年, $\mathrm{Wu}$ 等 ${ }^{[51]}$ 报道了在可见光照射下仲胺与 $\beta-$ 酮酯化合物的氧化偶联反应(Eq. 36). 该反应体系用 Cat*9 $\left[\mathrm{Ru}(\mathbf{L} 7)_{3} \mathrm{Cl}_{2}\right]$ 作催化剂, $\mathrm{Cu}(\mathrm{OTf})_{2}$ 作辅助催化剂, 空气中的氧气为氧化剂, 甲苯为溶剂; 其中 Cat*9 是由 $\mathrm{RuCl}_{2}$ 和 $\mathbf{L 7}$ 合成的; 空气中的氧气在该反应中起到了很 重要的作用, 若反应体系中没有氧气, 则反应根本不能 发生. 对反应广普性研究发现无论带有供电子基还是吸 电子基的芳基仲胺和 $\beta$-酮酯化合物反应都得到了中等 到较好的收率 $(52 \% \sim 93 \%)$.

2013 年, 陈阔等 ${ }^{[52]}$ 报道了在氮气保护下以联吡啶 钌配合物 Cat*10 $\left[\mathrm{Ru}(\mathrm{dmbp})\left(\mathrm{H}_{2} \mathrm{O}\right)_{2}\right](\mathrm{OTf})_{3}$ 作催化剂对末

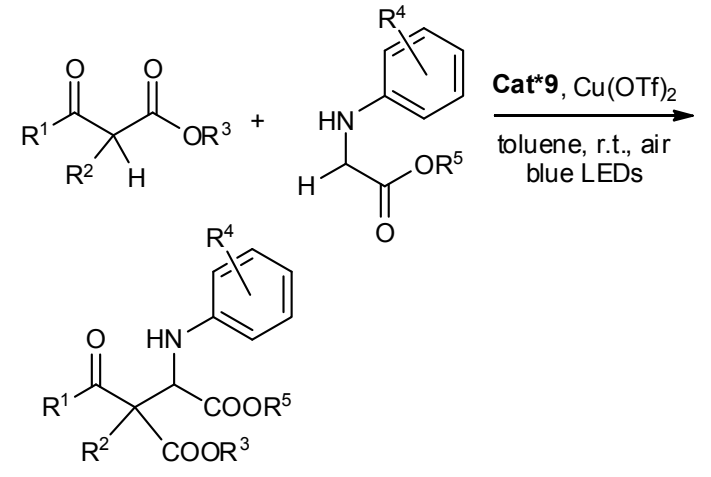

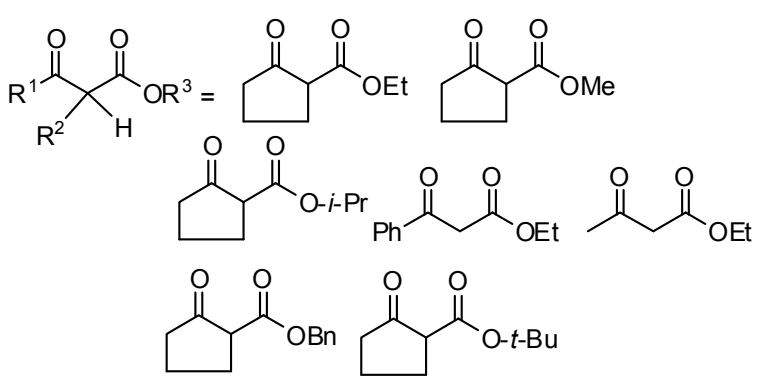

$\mathrm{R}^{4}=\mathrm{MeO}, \mathrm{Cl} ; \mathrm{R}^{5}=\mathrm{Me}, \mathrm{Et}, \mathrm{Bn}$

端炔烃的催化聚合成环反应(Eq. 37). 该反应用 THF 和 水的混合液(体积比为 $1: 1$ ) 作溶剂, 在回流条件下进 行; 其中 $\mathbf{C a t} * 10$ 是由 $\mathrm{RuCl}_{3}, \mathbf{L 1 0}, \mathrm{AgOTf}$ 和水合成的.

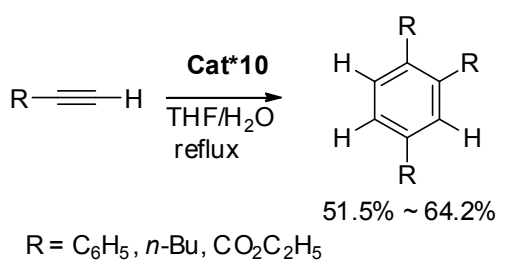

需注意的是反应中如不加入催化剂，则反应根本无 法进行. 反应的广普性研究表明 1-已炔, 苯乙炔和丙炔 酸乙酯均可得到 $51.5 \% \sim 64.7 \%$ 的收率，而其它炔类化 合物本文并未研究.

\section{$1.2 \mathrm{C}-\mathrm{N}$ 键的形成}

2009 年, Zhou 等 ${ }^{[53]}$ 报道了一种新颖的联吡啶氮氧 化物配体 $\mathbf{L 9}$, 它与铜盐 $\mathrm{CuSO}_{4}$ 结合, 在水相中且不加任 何相转移催化剂的条件下, 以 $\mathrm{Cs}_{2} \mathrm{CO}_{3}$ 作碱, 于 $120{ }^{\circ} \mathrm{C}$ 下可以有效地催化氮上含氢的杂环胺与卤代芳烃(I 和 $\mathrm{Br}$ )的 $\mathrm{C}-\mathrm{N}$ 偶联反应(Eq. 38). 作者通过对各种配体的 篎选发现 $\mathbf{L 9}$ 对该反应有很好的促进作用. 这可能是由 于 L9 不仅在水中有很好的溶解性，其结构也有很大的 灵活性. 反应的广普性研究表明碘代芳烃可以和杂环胺 有效反应，取得 78\% 95\%的收率; 吸电子基取代的溴 苯和杂环胺反应，可以取得 $69 \%$ ～ $89 \%$ 的收率; 而给电 子基取代的溴苯和杂环胺反应时，尽管增加了反应时间 也仅能得到 $32 \% \sim 47 \%$ 的收率. 需要注意的是该反应具 
有很高的化学选择性, 如对溴碘苯和咪唑反应时, 可以 得到 90\%收率的对溴苯基咪坐. 该催化体系对于连有氧 基, 美基和氨基取代的卤代芳烃有良好的官能团兼容性, 可以避免二苯醚或二苯胺等偶联副产物的生成, 如对于 杂环胺和带羟基或氨基的卤代芳烃的反应，无需对卤代 芳烃进行保护，只是反应仅能得到中等收率的产物.

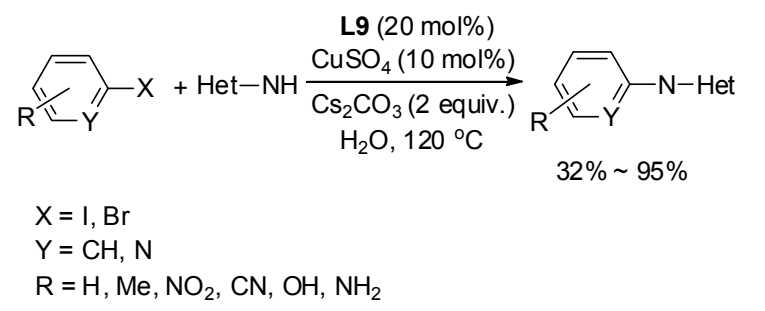

2013 年, Milstein 等 ${ }^{[54]}$ 报道了在氩气保护下联吡啶 $\mathrm{Ru}$ 类催化剂 Cat*11 催化伯醇与仲胺反应生成三级胺的 偶联反应(Eq. 39). 该反应以叔丁醇钾为碱, 甲苯为溶 剂, 在回流条件下反应, 催化剂的用量小于 $1 \mathrm{~mol} \%$. 反 应的广普性研究表明无论是芳香族还是脂肪族的仲胺 在 Cat*11 的催化作用下均能得到 50\% 88\%的收率.

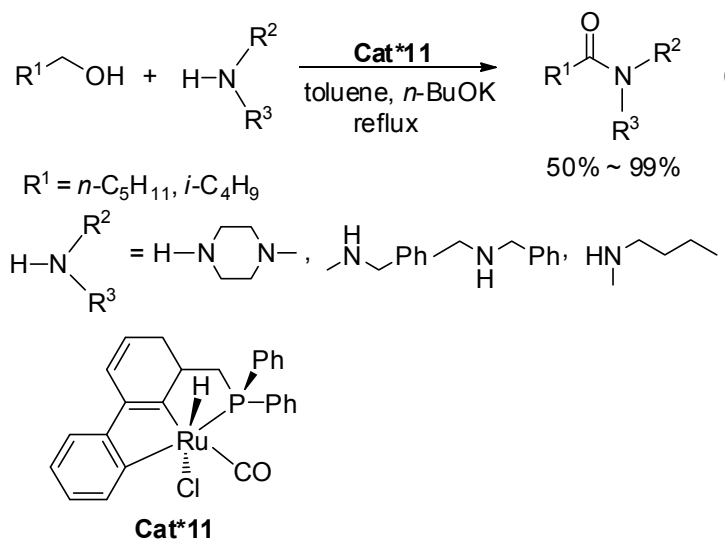

2013 年, Bhanage 等 ${ }^{[55]}$ 报道了基于 $\mathrm{Ni}(\mathrm{Py})_{4} \mathrm{Cl}_{2} / \mathbf{L} 7$ 催 化体系催化的炔烃、二卤甲烷和仲胺化合物的偶联反应 (Eq. 40). 该反应以 TMG (tetramethylguanidine)为碱, 乙 腈为溶剂, 于 $70{ }^{\circ} \mathrm{C}$ 下反应. 反应的广普性研究表明芳 香炔和杂环芳香炔分别与脂肪仲胺和二卤甲烷反应均

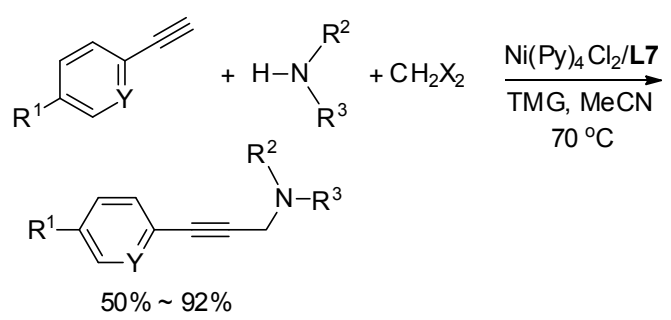

$\mathrm{R}^{1}=\mathrm{H}, \mathrm{Me}, \mathrm{MeO}, \mathrm{CF}_{3}, \mathrm{NH}_{2}, \mathrm{OH}$

$\mathrm{R}^{2}, \mathrm{R}^{3}=\mathrm{C}_{2} \mathrm{H}_{5}, \mathrm{C}_{3} \mathrm{H}_{7},-\left(\mathrm{CH}_{2}\right)_{4} \mathrm{O}-,-\left(\mathrm{CH}_{2}\right)_{5}-$ $\mathrm{X}=\mathrm{I}, \mathrm{Br}, \mathrm{Cl} ; \mathrm{Y}=\mathrm{CH}, \mathrm{N}$
可得到 $50 \%$ ～92\%的收率; 而脂肪炔和芳香胺由于活性 较低则根本不能参与反应. 需注意的是反应中二卤甲烷 的种类 $(\mathrm{I}, \mathrm{Br}$ 和 $\mathrm{Cl})$ 对反应收率无影响.

\section{$1.3 \mathrm{C}-\mathrm{S}$ 键的形成}

2009 年，Tsai 等 ${ }^{[56]}$ 发现结合联吡啶配体 L4, $\mathrm{FeCl}_{3} \cdot 6 \mathrm{H}_{2} \mathrm{O}$ 可以在水相中以 $\mathrm{KOH}$ 作碱于回流条件下有 效催化碘代芳烃和芳基硫醇的 $\mathrm{C}-\mathrm{S}$ 偶联，合成二芳基 硫醚(Eq. 41). 底物广普性研究表明在最优条件下, 无论 是连有供电子基还是吸电子基的碘代芳烃都可和苯硫 醇充分反应，得到 $82 \% \sim 99 \%$ 的收率; 但是吸电子基取 代的碘苯如对硝基碘苯与苄基硫醇的反应则不能很好 地进行，反应仅能得到 $25 \%$ 的收率，并且有一定的副产 物生成. 而值得注意的是, 该水相体系无需相转移催化 剂，无需情性气体保护，后处理简单，而且反应液经过 有机溶剂萃取回收，经过纯化即可得到产物，而水相重 复使用六次后，在相同的时间内反应取得的收率从 $92 \%$ 降低到 74\%.

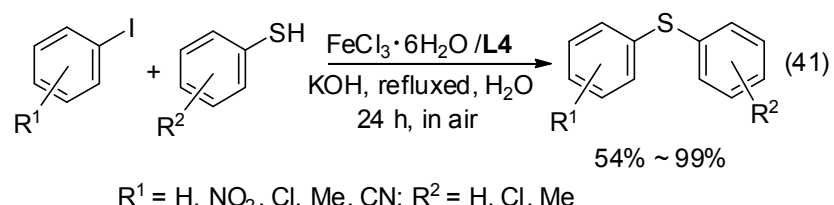

2011 年, Tsai 等 ${ }^{[57]}$ 报道了用 $\mathrm{CoCl}_{2} \cdot 6 \mathrm{H}_{2} \mathrm{O} / \mathbf{L} 7$ 催化体 系催化卤代芳烃 $(\mathrm{I}, \mathrm{Br}$ 和 $\mathrm{Cl})$ 和硫醇的 $\mathrm{C}-\mathrm{S}$ 偶联反应 (Eq. 42). 该催化体系用 $\mathrm{Zn}$ 作还原剂, $\mathrm{KOH}$ 为碱，水为 溶剂，于 $100{ }^{\circ} \mathrm{C}$ 下反应; 其中 $\mathbf{L 7}$ 和 $\mathrm{Zn}$ 的加入可有效地 提高反应收率. 反应的广普性研究表明无论是供电子基 还是吸电子基取代的碘代芳烃和溴代芳烃与芳基硫醇 反应均可得到 $53 \% \sim 99 \%$ 的收率，而脂肪硫醇仅能得到 26\% 51\%的收率; 氯代芳烃由于活性较低与芳基硫醇 反应仅能得到 $30 \% \sim 56 \%$ 的收率.

$$
\begin{aligned}
& \mathrm{Ar}-\mathrm{X}+\mathrm{R}-\mathrm{SH} \underset{\mathrm{Zn}, \mathrm{KOH}, \mathrm{H}_{2} \mathrm{O}}{\stackrel{\mathrm{CoCl}_{2} \cdot 6 \mathrm{H}_{2} \mathrm{O} / \mathrm{L} 7}{\longrightarrow}} \mathrm{Ar}^{2} \mathrm{Ar}^{\circ} \mathrm{C} \\
& 32 \% \sim 99 \% \\
& \mathrm{R}=\text { aryl, alkyl; } \mathrm{X}=\mathrm{I}, \mathrm{Br}, \mathrm{Cl}
\end{aligned}
$$

2013 年, $\mathrm{Noël}$ 等 ${ }^{[58]}$ 报道了以 $\left[\mathrm{Ru}(\mathbf{L} 7)_{3} \mathrm{Cl}_{2}\right] \cdot 6 \mathrm{H}_{2} \mathrm{O}$ 作催 化剂在可见光照射下硫醇与芳香胺偶联生成硫醚的反 应(Eq. 43). 该反应以 $\mathrm{TsOH} \cdot \mathrm{H}_{2} \mathrm{O}$ 为酸源, $t$ - $\mathrm{BuONO}$ 为添

$$
\begin{aligned}
& \mathrm{R}-\mathrm{SH}+\mathrm{Ar}-\mathrm{NH}_{2} \frac{\left[\mathrm{Ru}(\mathbf{L 7})_{3} \mathrm{Cl}_{2}\right] \cdot 6 \mathrm{H}_{2} \mathrm{O}}{\underset{\mathrm{TsOH} \cdot \mathrm{H}_{2} \mathrm{O}, t-\mathrm{BuONO}}{\mathrm{CH}} \mathrm{R}_{3} \mathrm{CN}, \mathrm{rt.}} 21 \% \sim 91 \% \\
& \mathrm{R}=\mathrm{MeOC}_{6} \mathrm{H}_{4}, \mathrm{HOC}_{6} \mathrm{H}_{4} \\
& \mathrm{CF}_{3} \mathrm{C}_{6} \mathrm{H}_{4}, \mathrm{CH}_{3}\left(\mathrm{CH}_{2}\right)_{7}, \square \cdots,
\end{aligned}
$$


加剂, 乙腈为溶剂, 在室温下反应; 其中 $t$-BuONO 的加 入可以有效地提高反应收率. 反应广普性研究表明除 4甲氧基苯硫酚和 6-氨基喹啉反应仅能得到 21\%的收率 外, 其它无论是芳香硫酚、杂芳香硫酚还是脂肪硫醇与 芳香胺反应均可取得中等到较好的收率 (50\% 91\%).

\section{$1.4 \mathrm{C}-\mathrm{O}$ 键的形成}

2009 年, Akita 等 ${ }^{[59]}$ 报道了在光照条件下醛和烯胺 类化合物分别与 TEMPO 发生的氧化偶联反应(Eqs. 44, 45). 该反应以 $\mathbf{C a t} * 12\left[\mathrm{Ru}(\mathbf{L} 7)_{3} \mathrm{~TB}(\mathrm{II}) \cdot\left(\mathrm{PF}_{6}\right)_{2}\right]$ 作催化剂, 乙腈为溶剂, 在室温下反应. 需注意的是该反应需在光 照下反应, 否则反应根本无法进行; 且醛进行反应时还 需在反应体系中加入吗啉 (morpholine) 作辅助催化剂. 反应广普性研究表明脂肪烯胺和芳香烯胺参与反应时 均可得到 $81 \% \sim 84 \%$ 的收率; 芳香和直连的脂肪醛类化 合物可得到 $40 \% \sim 68 \%$ 的收率; 而环烷烃取代的醛如环 己基甲醛根本不能发生反应.
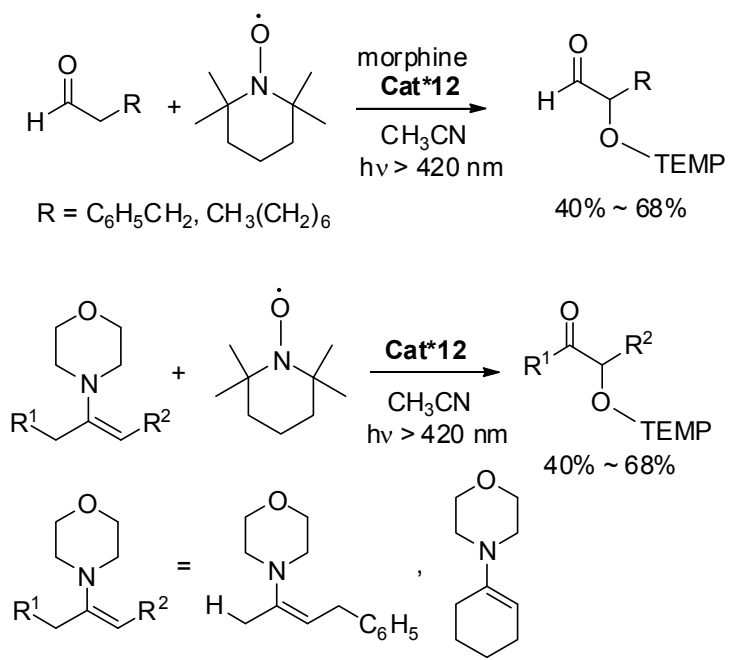

2013 年, Phan 等 ${ }^{[60]}$ 首次报道了使用非均相催化剂 Cat*13 $\left[\mathrm{Cu}_{2}(\mathrm{BPDC})_{2}(\mathbf{L 1 1})\right]$ 催化醚类化合物和邻位官能 团取代的苯酚发生的脱氢偶联反应(Eq. 46). 催化剂 Cat*13 是用 $\mathrm{Cu}\left(\mathrm{NO}_{3}\right)_{2} \bullet \mathrm{H}_{2} \mathrm{O}, \mathrm{H}_{2} \mathrm{BPDC}$ 和 $\mathbf{L 1 1}$ 合成的. 该 研究以 2-羟基苯甲醛和 1,4-二氧六环的反应作标准反应 进行考察. 经实验发现, 反应无需加入辅助溶剂, 以 TBHP(过氧叔丁醇)作氧化剂, Cat*13 为催化剂, 于 100 ${ }^{\circ} \mathrm{C}$ 下反应 $2 \mathrm{~h}$ 就可完全反应, 转换率达到 $100 \%$. 反应广 普性研究表明无论带有供电子基还是吸电子基的邻位

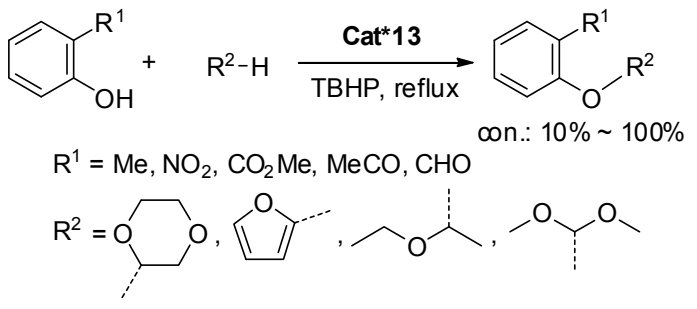

取代的苯酚和 1,4-二氧六环反应均可以取得中等到较好 的转换率 $(55 \% \sim 100 \%)$; 而乙醚、四氢呋喃、二甲氧基 甲烷由于沸点较低, 在回流条件下和 2-羟基苯甲醛反应 的转换率仅有 $10 \% \sim 20 \%$.

2013 年, Phan 等 ${ }^{[61]}$ 又将 Cat*13 用于邻位取代的酚 类化合物与 $N, N$-二烷基取代的甲酰胺类化合物的氧化 偶联中(Eq. 47). 该研究以 2-羊基苯甲醛和 DMF 的反应 作标准反应进行考察，经实验发现，反应无需加入辅助 溶剂, 以 $\mathrm{TBHP}$ (过氧叔丁醇)作氧化剂, Cat*13 为催化 剂, 于 $100{ }^{\circ} \mathrm{C}$ 下应 $2 \mathrm{~h}$ 就可完全反应，转换率达到 97\%. 反应广普性研究表明邻位取代基可增强苯酚的活 性，如苯酚和 DMF 反应仅能得到 $8 \%$ 的转换率; 而 2 -甲 醛基和 2-乙酰基取代的苯酚参与反应时的转换率则能 达到 92\% 97\%; 而 DMF, DEF 和 NFP 等甲酰胺类化合 物和 2-羊基苯甲醛反应均可取得中等到较好的转换率 (48\% 97\%).

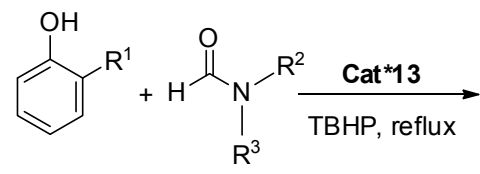

$\mathrm{R}^{1}=\mathrm{H}, \mathrm{Me}, \mathrm{CHO}, \mathrm{CO}_{2} \mathrm{Me}, \mathrm{MeCO}$

$\mathrm{R}^{2}=\mathrm{Me}, \mathrm{Et},\left(\mathrm{CH}_{2}\right)_{2}$ $\mathrm{R}^{3}=\mathrm{Me}, \mathrm{Et},\left(\mathrm{CH}_{2}\right)_{3}$

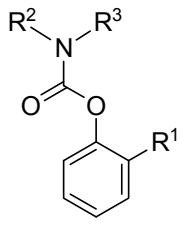

con: $8 \% \sim 97 \%$

\section{$1.5 \mathrm{C}-\mathrm{Se}$ 键的形成}

2000 年, Diaz 等 ${ }^{[2]}$ 报道了在 $\mathrm{N}_{2}$ 保护下二苯硒醚和 碘代芳烃(芳环和杂芳环)的 C-Se 键活化偶联(Eq. 48). 反应用 $(\mathbf{L} 7)_{2} \mathrm{NiBr}_{2}$ 作催化剂, $\mathrm{NaOH}$ 为碱，乙醇和 $\mathrm{THF}$ 的 混合液(体积比 $4: 1$ ) 为溶剂, 于 $65{ }^{\circ} \mathrm{C}$ 下反应. 需注意 的是反应体系需加入负载于树脂(resin)上的 $\mathrm{NaBH}_{4}$, 它 可避免副产物的生成. 反应广普性研究表明二苯硒醚的 电子效应和位阻效应对产物收率有很大影响, 如二苯硒 醚和 4-碘苯甲酸反应可得到 $77 \%$ 的收率; 而二-(4-氯)苯 基硒醚与二-(3,5-二叔丁基-6-OMOM)苯硒醚分别与 4碘苯甲酸反应仅能得到 14\%和 $25 \%$ 的收率，而杂芳环碘 化物比芳环碘化物收率更低，总体来说，大部分收率都 相对较低( $(9 \% \sim 85 \%)$.

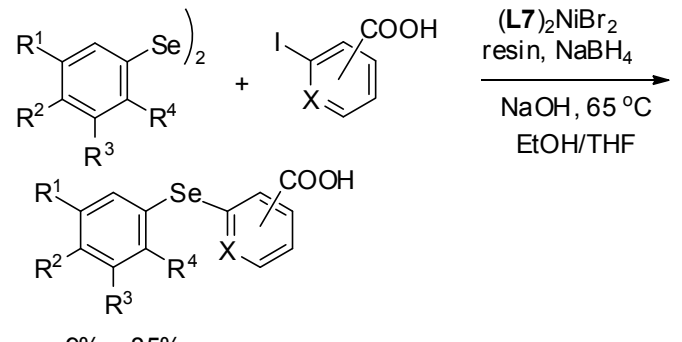

$\mathrm{R}^{1}, \mathrm{R}^{2}, \mathrm{R}^{3}, \mathrm{R}^{4}=\mathrm{H}, \mathrm{Me}, \mathrm{MeO}, t-\mathrm{Bu}, \mathrm{BnO}, \mathrm{OMOM}, \mathrm{CH}_{3}\left(\mathrm{CH}_{2}\right)_{5} \mathrm{O}$ $\mathrm{X}=\mathrm{CH}, \mathrm{N}, \mathrm{COMe}$ 


\section{2 结论与展望}

联吡啶配体有着比膦配体更强的氧化还原稳定性, 稳定性也好, 并且对水和氧气不敏感; 它的制备简单, 且部分已经商品化. 同时, 它们能与许多过渡金属很好 地配位, 合成的催化剂具有高效, 易回收的特性, 因此, 研究新型且更有实用价值的联吡啶配体和其金属配合 物催化剂成为了化学工作者的研究重点. 在过去的 10 多年间, 化学工作者对金属联吡啶类配合物进行了广泛 的研究, 其 $\mathrm{Pd}, \mathrm{Cu}$ 和 $\mathrm{Fe}$ 配合物在形成 $\mathrm{C}-\mathrm{C}$ 键的 Heck, Suzuki 和 Sonogashira 等反应中体现出良好的催化活性 和选择性, 具有潜在的工业应用价值. 但是, 要实现它 们在工业中的真正应用仍然有一定的距离, 也存在着一 些问题; 如在水相中反应大都需要高温回流, 并增加催 化剂用量, 且反应时间较长; 催化剂经多次回收使用后 活性明显降低. 这仍需要化学工作者对吡啶类配体和其 金属配合物催化剂的合成和催化活性作更深入的研究, 并实现其在工业化中的真正应用.

\section{References}

[1] Kawano, T.; Shinomaru, T.; Ueda, I. Org. Lett. 2002, 4, 2545.

[2] Sinner, F.; Buchmeiser, M. R.; Tessadri, R.; Mupa, M.; Wurst, K.; Bonn, G. K. J. Am. Chem. Soc. 1998, 120, 2790.

[3] Kaes, K.; Katz, K.; Hosseini, W. Chem. Rev. 2000, 100, 3553.

[4] Beccalli, E. M.; Broggini, G.; Martinelli, M.; Sottocornola, S. Chem. Rev. 2007, 107, 5318.

[5] Turner, N. J. Chem. Rev. 2011, 111, 4073.

[6] Beletskaya, I. P.; Ananikov, V. P. Chem. Rev. 2011, 111, 1596.

[7] Ullmann, F. Ber. Dtsch. Chem. Ges. 1903, 36, 2382.

[8] Zhang, B. B.; Zhan, D.; Zhang, X. P.; Xiang, Q. J.; Zeng, Q. L. Acta Chim. Sinica 2012, 70, 1655 (in Chinese). (张斌彬, 詹丹, 张小平, 向沁洁, 曾庆乐, 化学学报, 2012, 70, 1655.)

[9] Li, X.; Yan, X. Y.; Chang, H. H.; Wang, L. C.; Zhang, Y.; Chen, W. W.; Li, Y. W.; Wei, W. L. Org. Biomol. Chem. 2012, 10, 495.

[10] Li, X.; Wang, L. C.; Chang, H. H.; Zhang, C. X.; Wei, W. L. Appl. Catal. A: Gen. 2013, 462 463, 15.

[11] Yin, J.; Rainka, M. P.; Zhang, X. X.; Buchwald, S. L. J. Am. Chem. Soc. 2002, 124, 1162.

[12] Matthias, A.; Oberli, M. A.; Stephen, L.; Buchwald, S. L. Org. Lett. 2012, 14, 4606.

[13] Jiang, L.; Li, Z. N.; Zhao, D. F. Acta Chim. Sinica 2010, 30, 200 (in Chinese).

(姜岗, 李争宁, 赵德峰, 化学学报, 2012, 30, 200.)

[14] Paddock, R. L.; Nguyen, S. T. J. Am. Chem. Soc. 2001, 123, 11498.

[15] Mizoroki, T.; Mori, K.; Ozaki, A. Bull. Chem. Soc. Jpn. 1971, 44, 581.

[16] Heck, R. F.; Nolley, J. P. J. Org. Chem. 1972, 14, 2320

[17] Nájera, C.; Gil-Moltó, J.; Karlstrëm, S.; Falvello, L. R. Org. Lett. 2003, 5,1451

[18] Tsai, F. Y.; Wu, C. L.; Mou, C. Y.; Chao, M. C.; Lin, H. P.; Liu, S. T. Tetrahedron Lett. 2004, 45, 7503 .

[19] Gil-Moltó, J.; Karlstrëm, S.; Nájera, C. Tetrahedron 2005, 61, 12168.

[20] Huang, S. H.; Chen, J. R.; Tsai, F. Y. Molecules 2010, 15, 315.

[21] Jatap, S. V.; Deshpande, R. M. Kinet. Catal. 2013, 54, 314.

[22] Miyauar, N.; Suzuki, A. Chem. Rev. 1995, 95, 2457.
[23] Suzuki, A. Organomet. Chem. 1999, 576, 147.

[24] Nájera, C.; Gil-Moltó, J.; Karlstrom, S. Adv. Synth. Catal. 2004, 346,1798

[25] Wu, W. Y.; Chen, S. N.; Tsai, F. Y. Tetrahedron Lett. 2006, 47, 9267.

[26] Osako, T.; Uozumi, Y. Heterocycles 2010, 80, 505.

[27] Huang, J. P.; Wang, W.; Li, H. X. ACS Catal. 2013, 3, 1526.

[28] Negishi, E. I.; Baba, S. J. Chem. Soc., Chem. Commun. 1976, 15, 596.

[29] Baba, S.; Negishi, E. I. J. Am. Chem. Soc. 1976, 98, 6729.

[30] Wu, W. Y.; Lin, T. C.; Takahashi, T.; Tsai, F. Y.; Mou, C. Y. ChemCatChem 2013, 5, 1011.

[31] Hatanaka, Y.; Hiyama, T. J. Org. Chem. 1988, 53, 918.

[32] Chen, S. N.; Wu, W. Y.; Tsai, F. Y. Tetrahedron 2008, 64, 8164.

[33] Corriu, R. J. P.; Masse, J. P. J. Chem. Soc., Chem. Commun. 1972, 3,144 .

[34] Tamao, K.; Sumitani, K.; Kumada, M. J. Am. Chem. Soc. 1972, 94 , 4374.

[35] Tsai, F. Y.; Lin, B. N.; Chen, M. J.; Mou, C. Y.; Liu, S. T. Tetrahedron 2007, 63, 4304

[36] Sonogashira, K. Organomet. Chem. 2002, 653, 46.

[37] Gil-Moltó, J.; Nájera, C. Eur. J. Org. Chem. 2005, 19, 4073.

[38] Lin, B. N.; Huang, S. H.; Wu, W. Y.; Mou, C. Y.; Tsai, F. Y. Molecules 2010, 15, 9157.

[39] Hung, T. T.; Huang, C. M.; Tsai, F. Y. ChemCatChem 2012, 4, 540.

[40] Fang, J. H.; Hu, M. J.; Wang, J. R.; Fu, Z. Q. J. Mol. Catal. 2006, 20,335 (in Chinese).

(房江华, 胡敏杰, 王家荣, 付志强, 分子催化, 2006, 20, 335.)

[41] Wang, Y. H.; Tsai, F. Y. Chem. Lett. 2007, 36, 1492.

[42] Chen, S. N.; Wu, W. Y.; Tsai, F. Y. Green Chem. 2009, 11, 269.

[43] Wu, T. M.; Huang, S. H.; Tsai, F. Y. Appl. Organomet. Chem. 2011, 25, 395.

[44] Yamamoto, T. Chem. Lett. 2012, 41, 1422.

[45] Chen, J. Y.; Chen, S. C.; Tang, Y. J.; Mou, C. Y.; Tsai, F. Y. J. Mol. Catal. A: Chem. 2009, 307, 88.

[46] Chen, J. Y.; Lin, T. C.; Chen, S. C.; Chen, A. J.; Mou, C. Y.; Tsai, F. Y. Tetrahedron 2009, 65, 10134

[47] Nishihara, Y.; Ogawa, D.; Noyori, S.; Iwasaki, M. Chem. Lett. 2012, 41, 1503.

[48] Kohls, P.; Jadhav, D.; Pandey, G.; Reiser, O. Org. Lett. 2012, 14, 672.

[49] Savmarker, J.; Rydfjord, J.; Gising, J.; Odell, L. R.; Larhed, M. Org. Lett. 2012, 14, 2393.

[50] Yasu, Y.; Koike, T.; Akita, M. Chem. Commun. 2012, 48, 5355.

[51] Gao, X. W.; Meng, Q. Y.; Xing, M.; Chen. B.; Feng, K.; Tung, C. H.; Wu, L. Z. Adv. Synth. Catal. 2013, 355, 2158.

[52] Yi, C. Q.; Cheng, J.; Zhang, P. Chen, K. J. Wuhan Inst. Technol. 2013, 35, 1 (in Chinese). (尹传奇, 成军, 张平, 陈阔, 武汉工程大学学报, 2013, 35, 1.)

[53] Liang, L.; Li, Z. K.; Zhou, X. G. Org. Lett. 2009, 11, 3294.

[54] Srimani, D.; Balaraman, E.; Hu, P.; Yehoshoa, B. D.; Milstein, D. Adv. Synth. Catal. 2013, 355, 2525.

[55] Lanke, S. R.; Bhanage, B. M. Appl. Organomet. Chem. 2013, 27, 729.

[56] Wu, W. Y.; Wang, J. C.; Tsai, F. Y. Green Chem. 2009, 11, 326.

[57] Lan, M. T.; Wu, W. Y.; Huang, S. H.; Luo, K. L.; Tsai, F. Y. RSC Adv. 2011, 1, 1751.

[58] Wang, X.; Cuny, G. D.; Noël, T. Angew. Chem., Int. Ed. 2013, 52, 7860.

[59] Koike, T.; Akita, M. Chem. Lett. 2009, 38, 166.

[60] Phan, N. T. S.; Vu, P. H. L.; Nguyen, T. T. J. Catal. 2013, 306, 38.

[61] Phan, N. T. S.; Nguyen, T. T.; Vu, P. H. L. ChemCatChem 2013, 5, 3068.

[62] Millois, C.; Diaz, P. Org. Lett. 2000, 2, 1705.

(Zhao, C.) 